\title{
Shank promotes action potential repolarization by recruiting BK channels to calcium nanodomains
}

Luna Gao ${ }^{1,2}$, Jian Zhao ${ }^{1,2}$, Evan Ardiel $^{1,2}$, Qi Hall ${ }^{1}$, Stephen Nurrish ${ }^{1,2}$, and Joshua M.

Kaplan $1,2,3, \#$

${ }^{1}$ Department of Molecular Biology, Massachusetts General Hospital, Boston, MA 02114, USA

${ }^{2}$ Department of Neurobiology, Harvard Medical School, Boston, MA 02115, USA

${ }^{3}$ Program in Neuroscience, Harvard Medical School

${ }^{\#}$ Corresponding author:

Joshua M. Kaplan, Ph.D.

Department of Molecular Biology

Simches 7

Massachusetts General Hospital

185 Cambridge St.

Boston, MA 02114

Tel: 617-726-5900

Fax: 617-726-5949

kaplan@molbio.mgh.harvard.edu 


\section{Summary:}

Mutations altering the scaffolding protein Shank are linked to several psychiatric disorders, and to synaptic and behavioral defects in mice. Among its many binding partners, Shank directly binds CaV1 voltage activated calcium channels. Here we show that the $C$. elegans $\mathrm{SHN}-1 / \mathrm{Shank}$ promotes CaV1 coupling to calcium activated potassium channels. Mutations inactivating SHN-1, and those preventing SHN-1 binding to EGL-19/CaV1 all increase action potential durations in body muscles. Action potential repolarization is mediated by two classes of potassium channels: SHK-1/KCNA and SLO-1 and SLO-2 BK channels. BK channels are calcium-dependent, and their activation requires tight coupling to EGL-19/CaV1 channels. SHN-1's effects on AP duration are mediated by changes in BK channels. In shn-1 mutants, SLO-2 currents and channel clustering are significantly decreased in both body muscles and neurons. Finally, increased and decreased shn-1 gene copy number produce similar changes in AP width and SLO-2 current. Collectively, these results suggest that an important function of Shank is to promote nanodomain coupling of BK with CaV1. 


\section{Introduction:}

Shank is a synaptic scaffolding protein (containing SH3, PDZ, proline-rich and SAM domains) (Grabrucker et al., 2011). Mammals have three Shank genes, each encoding multiple isoforms (Jiang and Ehlers, 2013). Several mouse Shank knockouts have been described but these mutants exhibit inconsistent (often contradictory) synaptic and behavioral defects (Jiang and Ehlers, 2013), most likely resulting from differences in the Shank isoforms impacted by each mutation. The biochemical mechanism by which Shank mutations alter synaptic function and behavior has not been determined.

In humans, Shank mutations and CNVs are linked to Autism Spectrum Disorders (ASD), schizophrenia, and mania (Durand et al., 2007; Peca et al., 2011). Haploinsufficiency for 22q13 (which spans the Shank3 locus) occurs in PhelanMcDermid syndrome (PMS), a syndromic form of ASD (Phelan and McDermid, 2012). PMS patients exhibit autistic behaviors accompanied by hypotonia, delayed speech, and intellectual disability (ID) (Bonaglia et al., 2011). Heterozygous inactivating Shank3 mutations are found in sporadic ASD and schizophrenia (Durand et al., 2007; Peca et al., 2011). A parallel set of genetic studies suggest that increased Shank3 function also contributes to psychiatric diseases. 22q13 duplications spanning Shank3 are found in ASD, schizophrenia, ADHD, and bipolar disorder (Durand et al., 2007; Failla et al., 2007; Han et al., 2013). A transgenic mouse that selectively over-expresses Shank3 exhibits hyperactive behavior and susceptibility to seizures (Han et al., 2013). Taken together, these studies suggest that too little or too much Shank3 can contribute to the pathophysiology underlying these psychiatric disorders.

Given its link to psychiatric disorders, there is great interest in determining how Shank regulates circuit development and function. Shank is highly enriched in the post- 
synaptic densities of excitatory synapses; consequently, most studies have focused on the idea that Shank proteins regulate some aspect of synapse formation or function. Through its various domains, Shank proteins bind many proteins (Lee et al., 2011; Sakai et al., 2011), thereby potentially altering diverse cellular functions. Shank proteins have been implicated in activity induced gene transcription (Perfitt et al., 2020; Pym et al., 2017), synaptic transmission (Zhou et al., 2016), synapse maturation (Harris et al., 2016), synaptic homeostasis (Tatavarty et al., 2020), cytoskeletal remodeling (Lilja et al., 2017), and sleep (Ingiosi et al., 2019). Each of these defects could contribute to the neurodevelopmental and cognitive deficits observed in ASD and schizophrenia.

Several recent studies suggest that an important function of Shank is to regulate the subcellular localization of ion channels. Shank mutations decrease the synaptic localization of NMDA and AMPA type glutamate receptors (Peca et al., 2011; Won et al., 2012). Other studies show that Shank proteins promote delivery of several ion channels to the plasma membrane, including HCN channels (Yi et al., 2016; Zhu et al., 2018), TRPV channels (Han et al., 2016), and CaV1 voltage activated calcium channels (Pym et al., 2017; Wang et al., 2017). Of these potential binding partners, we focus on CaV1 because human CACNA1C (which encodes a CaV1 $\alpha$-subunit) is mutated in Timothy Syndrome (TS), a rare monogenic form of ASD (Splawski et al., 2005; Splawski et al., 2004), and polymorphisms linked to CACNA1C are associated with multiple psychiatric disorders (Cross-Disorder Group of the Psychiatric Genomics, 2013). For this reason, we asked how Shank regulates the coupling of CaV1 channels to their downstream effectors.

C. elegans has a single Shank gene, shn-1. The SHN-1 protein lacks an SH3 domain but has all other domains found in mammalian Shank proteins. Mammalian 
Shank proteins directly bind CaV1 channels through both the SH3 and PDZ domains (Zhang et al., 2005). We previously showed that the SHN-1 PDZ domain directly binds to a carboxy-terminal ligand in EGL-19/CaV1 (Pym et al., 2017). CaV1 channels are tightly coupled to multiple downstream calcium activated pathways. C. elegans and mouse Shank proteins have been shown to promote CaV1 mediated activation of the transcription factor CREB (Perfitt et al., 2020; Pym et al., 2017).

Here we test the idea that $\mathrm{SHN}-1$ regulates $\mathrm{CaV} 1$ coupling to a second effector, calcium activated potassium currents (which are mediated by BK channels). BK channels are activated by both membrane depolarization and by cytoplasmic calcium. At resting cytoplasmic calcium levels $(\sim 100 \mathrm{nM})$, BK channels have extremely low open probability. Following depolarization, cytoplasmic calcium rises thereby activating BK channels. BK channels bind calcium with a $\mathrm{K}_{\mathrm{d}}$ ranging from 1-10 $\mu \mathrm{M}$ (Contreras et al., 2013); consequently, efficient BK channel activation requires tight spatial coupling to voltage activated calcium $(\mathrm{CaV})$ channels. $\mathrm{BK}$ channels associate with all classes of $\mathrm{CaV}$ channels (Berkefeld et al., 2006). The co-clustering of BK and $\mathrm{CaV}$ channels allows rapid activation of hyperpolarizing potassium currents following depolarization. BK channels decrease action potential (AP) durations, promote rapid after hyperpolarizations, decrease the duration of calcium entry, and limit secretion of neurotransmitters and hormones in neurons and muscles (Adams et al., 1982; Edgerton and Reinhart, 2003; Petersen and Maruyama, 1984; Storm, 1987). Thus, BK channels have profound effects on circuit activity.

C. elegans has two BK channel subunits (SLO-1 and SLO-2), both of which form calcium and voltage dependent potassium channels when heterologously expressed (Wang et al., 2001; Yuan et al., 2000). SLO-2 channels are also activated by cytoplasmic 
chloride (Yuan et al., 2000). As in mammals, neuronal SLO-1 and -2 channels inhibit neurotransmitter release (Liu et al., 2014; Liu et al., 2007; Sancar et al., 2011), presumably via their coupling to UNC-2/CaV2 and EGL-19/CaV1. In body muscles, SLO-1 channels are co-localized with EGL-19/CaV1 channels and regulate muscle excitability and behavior (Kim et al., 2009). Here we show that SHN-1 promotes BK coupling to EGL-19/CaV1 channels, thereby decreasing AP duration. 


\section{Results:}

\section{SHN-1 acts in muscles to regulate action potential duration}

EGL-19/CaV1 channels mediate the primary depolarizing current during body muscle APs (Jospin et al., 2002; Liu et al., 2011). Because SHN-1 directly binds EGL-19 (Pym et al., 2017), we asked if SHN-1 regulates muscle AP firing patterns. In WT animals, body muscles exhibit a pattern of spontaneous AP bursts ( 10 APs/burst; burst frequency $0.1 \mathrm{~Hz}$ ) (Fig. 1A). Within a burst, APs became progressively wider (Fig. 1B). A similar pattern of progressive AP broadening during burst firing has been reported for many neurons (Geiger and Jonas, 2000; Jackson et al., 1991). Outward potassium currents were progressively decreased during repetitive depolarization (Fig. 1C), suggesting that progressive AP broadening most likely results from accumulation of inactivated potassium channels during bursts, as seen in other cell types (Geiger and Jonas, 2000; Kole et al., 2007). Occasionally, WT muscles also exhibited prolonged depolarizations (>150 ms), which are hereafter designated plateau potentials (PPs). PPs often occur at the end of an AP burst (Fig. 1A).

In shn-1 null mutants, PP frequency and AP widths were significantly increased, AP amplitudes were decreased, resting membrane potential (RMP) was depolarized, while AP frequency and input resistance were unaltered (Fig. 1D-I). Similar increases in AP widths and PP frequency were observed in three, independently derived shn- 1 null mutants (nu712, nu652, and tm488) (Table 1). Single cell RNA sequencing studies suggest that $\mathrm{SHN}-1$ is expressed in muscles, neurons, glia, and epithelial cells (Cao et al., 2017; Packer et al., 2019), consistent with the broad expression of split GFP tagged shn1(nu600 $\left.\mathrm{GFP}_{11}\right)$ (Fig. 1 supplement 1). To determine if SHN-1 functions in body muscles to control AP duration, we edited the endogenous shn-1 locus to construct alleles that are 
either inactivated (nu697) or rescued (nu652) by the CRE recombinase (Fig. 2A). Using these alleles, we found that AP widths and PP frequency were increased in shn-1(muscle Knockout, KO) and that this defect was eliminated in shn-1(muscle rescue) (Fig. 2B-D). By contrast, shn- 1 knockout in neurons had no effect on PP rate or AP widths (Fig. 2CD). Because CRE expression in muscles produced opposite changes in AP firing patterns in strains containing the shn-1 nu697 and nu652 alleles, these results are unlikely to be caused by toxicity associated with CRE expression (Speed et al., 2019). Collectively, these results suggest that SHN-1 acts in body muscles to control AP duration.

\section{SHN-1 binding to EGL-19 promotes AP repolarization}

Because SHN-1 has multiple binding partners, we sought to confirm that prolonged APs result from decreased SHN-1 binding to EGL-19. To address this question, we recorded APs in strains containing mutations that disrupt this interaction (Fig. 3A). PP frequency was significantly increased by a deletion removing the EGL-19 carboxy-terminal PDZ ligand [egl-19(nu496 $\Delta$ VTTL)] (Fig. 3B). AP widths were significantly increased by a deletion removing the SHN-1 PDZ domain [shn-1(nu542 $\Delta \mathrm{PDZ})]$ and by the egl-19(nu496 $\Delta \mathrm{VTTL}$ ) mutation (Fig. 3C). These results support the idea that SHN-1 binding to EGL-19/CaV1 accelerates AP repolarization.

\section{AP repolarization is controlled by SHK-1 KCNA and SLO-1/2 BK channels}

To investigate how SHN-1 controls AP duration, we first asked which potassium channels promote repolarization following APs. Prior studies showed that voltageactivated potassium currents in body muscles are mediated by SHK-1/KCNA and BK channels (Gao and Zhen, 2011; Liu et al., 2011). SHK-1 channel function can be assessed 
in recordings using an internal solution containing low chloride levels (hereafter $\mathrm{Ik}_{\mathrm{loCl}}$ ). $\mathrm{Ik}_{\mathrm{loCl}}$ was nearly eliminated in $s h k-1$ single mutants (Fig. 4A-B). BK channel function can be assayed in recordings utilizing internal solutions with high chloride levels (hereafter $\mathrm{Ik}_{\mathrm{hiCl}}$ ), which activates SLO-2 channels (Yuan et al., 2000). $\mathrm{Ik}_{\mathrm{hiCl}}$ was $\sim 50 \%$ reduced in single mutants lacking either SLO-2 or SHK-1 and was eliminated in slo-2; shk-1 double mutants (Fig. 4C-D). These results suggest that SHK-1/KCNA and SLO-2/BK are the primary channels promoting AP repolarization. Consistent with this idea, AP duration was significantly increased in mutants lacking SHK-1/KCNA (Fig. 4E-F), as previously reported (Gao and Zhen, 2011; Liu et al., 2011).

Contradictory results have been reported for AP firing patterns in slo- 1 and slo-2 BK mutants (Gao and Zhen, 2011; Liu et al., 2011). These studies used intracellular solutions that alter BK channel function. In (Liu et al., 2011), an intracellular solution containing high chloride levels was used, thereby exaggerating SLO-2's contribution to AP repolarization (Yuan et al., 2000). In (Gao and Zhen, 2011), an intracellular solution containing a fast calcium chelator (BAPTA) was used, which inhibits BK activation thereby minimizing their impact on APs. We re-investigated the effect of SLO channels on APs using intracellular solutions with low chloride and a slow calcium chelator (EGTA), finding that AP durations were increased to a similar extent in slo- 1 and slo-2 single mutants (Fig. 4E-F). Taken together these results confirm that SHK-1 and SLO are the primary channels promoting AP repolarization in body muscles.

\section{SLO-1 and SLO-2 function together to promote AP repolarization}

SLO-1 and SLO-2 subunits are co-expressed in muscles and could potentially coassemble to form heteromeric channels. To determine if channels containing both SLO-1 
and SLO-2 regulate AP repolarization, we analyzed AP widths in slo-1; slo-2 double mutants. AP widths in slo-1; slo-2 double mutants were not significantly different from those found in the single mutants (Fig. 4F). Because slo- 1 and slo-2 mutations did not have additive effects on AP widths, these results support the idea that heteromeric SLO1/2 channels mediate rapid repolarization of muscle APs.

We did several experiments to further test the idea that SLO-1 and SLO-2 function together in heteromeric channels. First, we recorded voltage activated potassium current in body muscles and found that $\mathrm{Ik}_{\mathrm{hiCl}}$ was modestly reduced in slo- 1 mutants, was dramatically reduced in slo-2 mutants, and was not further reduced in slo- 1 ; slo-2 double mutants (Fig. 5A-B). These results suggest that $\mathrm{Ik}_{\mathrm{hiCl}}$ is mediated by heteromeric channels (containing both SLO-1 and SLO-2 subunits) and by SLO-2 homomers.

As a final test of this idea, we asked if subcellular localization of SLO-1 and SLO-2 subunits requires expression of both subunits. For this analysis, endogenous SLO1 and SLO-2 subunits were labelled with split GFP. Using CRISPR, we introduced the eleventh $\beta$-strand of GFP $\left(\mathrm{GFP}_{11}\right)$ into the endogenous slo- 1 and slo- 2 genes and visualized their expression by expressing $\mathrm{GFP}_{1-10}$ in body muscles. Strains containing the $\mathrm{GFP}_{11}$ tagged alleles exhibited wild type $\mathrm{Ik}_{\mathrm{hiCl}}$ currents, AP widths, and RMP, indicating that the tag did not interfere with SLO channel function (Fig. 5 supplement 1). Using these alleles, we find that SLO-2 puncta intensity was significantly reduced in slo- 1 null mutants, indicating that channels containing SLO-2 subunits require SLO-1 for their trafficking (Fig. 5C-D). By contrast, SLO-1 puncta intensity was unaffected in slo-2 mutants, suggesting that BK channels lacking SLO-2 were trafficked normally (Fig. 5EF). Collectively, these results suggest that rapid muscle repolarization following APs is mediated by SLO-1/2 heteromeric channels. Two prior studies also suggested that SLO 
subunits form heteromeric channels when heterologously expressed in Xenopus oocytes.

SLO-1 currents were inhibited by a dominant-negative SLO-2 construct (Yuan et al., 2000). Similarly, mammalian SLO2 subunits (KCNT1 and 2) co-assemble to form heteromeric channels (Chen et al., 2009). Our results suggest that endogenously expressed SLO subunits also form heteromeric channels in native tissues.

\section{SHN-1 controls AP duration through BK channels}

SHN-1's impact on AP duration could be mediated by changes in either SHK-1 or SLO channels. To determine if SHN-1 acts through SLO channels, we asked if slo-2 mutations block SHN-1's effects on AP widths. Consistent with this idea, AP widths in slo-2 single mutants were not significantly different from those in slo-2 double mutants containing shn-1(nu712 null), shn-1(nu542 $\Delta \mathrm{PDZ})$, or egl-19(nu496 $\Delta \mathrm{VTTL})$ mutations

(Fig. 6A). These results suggest that SHN-1 controls AP duration by regulating SLO-2 channels.

To confirm that SHN-1 regulates SLO-2 channels, we analyzed potassium currents in shn-1 mutants. A shn-1 null mutation had no effect on $\mathrm{Ik}_{\mathrm{loCl}}$ currents, indicating that SHK-1 function was unaffected (Fig. 6B-C). By contrast, $\mathrm{Ik}_{\mathrm{hiCl}}$ was $\sim 30 \%$ reduced in shn-1 null mutants, $\sim 50 \%$ reduced in slo-2 mutants, and was not further reduced in shn-1; slo-2 double mutants (Fig. 6D-E). Lack of additivity in shn-1; slo-2 double mutants suggests that the SHN-1 sensitive potassium current was mediated by

SLO-2. A similar decrease in $\mathrm{Ik}_{\mathrm{hiCl}}$ current was observed in shn-1(nu542 $\left.\Delta \mathrm{PDZ}\right)$ mutants

(Fig. 6E). Ik $\mathrm{hiCl}_{\mathrm{hl}}$ current was unaltered in egl-19(nu496 $\left.\Delta \mathrm{VTTL}\right)$ mutants, implying that SHN-1 binding to EGL-19's carboxy terminus is not required for SLO-2 current (Fig. $6 \mathrm{E})$. Thus, shn-1 inactivation decreased SLO-1/2 BK current but had little or no effect on 
SHK-1 KCNA current; consequently, SHN-1 regulates AP widths by promoting activation of SLO-1/2 channels.

\section{SHN-1 promotes nanodomain coupling of SLO-2 with EGL-19/CaV1 channels}

BK channels bind calcium with affinities ranging from 1-10 $\mu \mathrm{M}$ (Contreras et al., 2013). As a result of this calcium dependence, BK channels have very low open probability at resting cytoplasmic calcium levels $(\sim 100 \mathrm{nM})$ and efficient BK activation typically requires close spatial coupling to calcium channels (Barrett et al., 1982). We next asked if body muscle BK channels are functionally coupled to EGL-19/CaV1 channels. Consistent with this idea, $\mathrm{Ik}_{\mathrm{hicl}}$ current was significantly decreased by nemadipine, an EGL-19/CaV1 antagonist (Fig. 7A-B) (Kwok et al., 2008). The inhibitory effect of nemadipine on $\mathrm{Ik}_{\mathrm{hiCl}}$ was eliminated in slo-2 mutants (Fig. 7A-B), suggesting that the nemadipine sensitive potassium current was mediated by SLO-2.

Is EGL-19 coupling to SLO-2 mediated by nanodomain signaling? To test this idea, we compared $\mathrm{Ik}_{\mathrm{hiCl}}$ and $\mathrm{AP}$ widths recorded with intracellular solutions containing fast (BAPTA) and slow (EGTA) calcium chelators (Fig. 7C-E). We found that $\mathrm{Ik}_{\mathrm{hiCl}}$ recorded with BAPTA was significantly smaller than that recorded with EGTA (Fig. 7C). Similarly, AP widths recorded with BAPTA were significantly longer than those recorded with EGTA (Fig. 7D-E). The effect of BAPTA on $\mathrm{Ik}_{\mathrm{hicl}}$ and AP widths was eliminated in slo-2 mutants (Fig. 7C,E), suggesting that the BAPTA sensitive potassium current is mediated by SLO-2. BAPTA's effect on $\mathrm{Ik}_{\mathrm{hicl}}$ and AP widths was reduced but not eliminated in shn-1 mutants (Fig. 7C,E), consistent with the partial loss of SLO-2 current in these mutants (Fig. 6D-E). Taken together, these results suggest that SHN-1 promotes SLO-2 nanodomain coupling to EGL-19/CaV1. 
If BK channels are functionally coupled to EGL-19/CaV1, these channels should be co-localized. Endogenous SLO-2 channels (tagged with GFP $_{11}$ ) were distributed in a punctate pattern on the muscle surface. A subset of the SLO-2 puncta co-localized with EGL-19/CaV1 channels (tagged with Cherry11), suggesting that EGL-19 nanocomplexes are heterogeneous (Fig. 7F). SLO-2 puncta intensity was significantly reduced in shn-1 null mutants (Fig. 7F-G), consistent with the decreased SLO-2 current observed in these mutants. By contrast, SLO-2 puncta intensity was unaltered in shn-1(nu542 $\Delta$ PDZ) and egl-19(nu496 $\Delta$ VTTL) mutants (Fig. 7G), in which SHN-1 binding to EGL-19's cterminus is disrupted (Pym et al., 2017). SLO-1 puncta intensity was unaltered in shn-1 null mutants, indicating that BK channels lacking SLO-2 were trafficked normally (Fig. 7 supplement 1). Collectively, these results suggest that SHN-1 stabilizes SLO-2 clusters in the plasma membrane and promotes activation of heteromeric SLO-1/2 channels by nearby calcium channels.

\section{EGL-19 to SLO-2 coupling is sensitive to shn-1 gene dose}

Deletion and duplication of human shank genes are both associated with ASD, schizophrenia, and mania (Bonaglia et al., 2006; Durand et al., 2007; Failla et al., 2007; Gauthier et al., 2010; Han et al., 2013). These results suggest that Shank phenotypes relevant to psychiatric disorders should exhibit a similar sensitivity to Shank copy number. For this reason, we analyzed the effect of $s h n-1$ gene dosage on $\mathrm{Ik}_{\mathrm{hicl}}$ and AP duration (Fig. 8). We analyzed animals with 1 (nu712/+ heterozygotes), 2 (WT), and 4 (WT+2 single copy shn-1 transgenes) copies of $s h n-1$. Compared to wild type controls, muscle $\mathrm{Ik}_{\mathrm{hiCl}}$ was significantly decreased while AP duration was significantly increased in 
animals containing 1 and 4 copies of $s h n-1$ (Fig. 8). Thus, increased and decreased shn- 1 gene dosage produced similar defects in AP duration and SLO-2 current.

\section{$\mathrm{SHN}-1$ regulates $\mathrm{BK}$ channel activation and neurotransmitter release in motor}

neurons

Thus far, our results suggest that SHN-1 promotes EGL-19 to SLO-2 coupling in muscles. We next asked if SHN-1 also promotes coupling in motor neurons. To test this idea, we analyzed $\mathrm{Ik}_{\mathrm{hiCl}}$ in cholinergic motor neurons and found that it was significantly reduced in shn-1 null mutants (Fig. 9A-C). The slo-2 and shn-1 mutations did not have additive effects on $\mathrm{Ik}_{\mathrm{hiCl}}$ in double mutants, suggesting that the $s h n-1$ mutation selectively decreases SLO-2 current in motor neurons (Fig. 9A-C). Consistent with decreased SLO-2 currents, we observed a corresponding decrease in axonal SLO-2(nu725 GFP $\left.{ }_{11}\right)$ puncta fluorescence in shn-1 mutant motor neurons (Fig. 9D-E). Thus, our results suggest that SHN-1 promotes EGL-19/CaV1 to SLO-2 coupling in both body muscles and cholinergic motor neurons. 


\section{Discussion:}

Our results lead to six principal conclusions. First, we show that SHN-1 acts cell autonomously in muscles to promote rapid repolarization of APs. Second, heteromeric BK channels containing both SLO-1 and SLO-2 subunits promote AP repolarization. Third, SHN-1 limits AP duration by promoting BK channel activation. Fourth, shn-1 mutants have decreased SLO-2 channel clustering and decreased SLO-2 currents. Fifth, increased and decreased SHN-1 gene dosage produce similar defects in AP durations and SLO-2 currents. And sixth, SHN-1 also promotes SLO-2 activation in motor neurons. Below we discuss the significance of these findings.

Shank as a regulator of ion channel density. Several recent studies suggest that an important function of Shank proteins is to regulate ion channel density and localization. Mutations inactivating Shank have been shown to decrease AMPA and NMDA receptor abundance and post-synaptic currents (Peca et al., 2011; Won et al., 2012), HCN channels (Yi et al., 2016; Zhu et al., 2018), TRPV channels (Han et al., 2016), and voltage activated CaV1 calcium channels (Pym et al., 2017; Wang et al., 2017). Here we show that Shank also regulates BK channel densities in C. elegans muscles and motor neurons. Collectively, these studies suggest that Shank proteins have the capacity to control localization of many ion channels, thereby shaping neuron and muscle excitability.

Shank regulation of BK channels could have broad effects on neuron and muscle function. In neurons, $\mathrm{BK}$ channels are functionally coupled to $\mathrm{CaV}$ channels in the soma and dendrites, thereby regulating AP firing patterns and somatodendritic calcium transients (Golding et al., 1999; Storm, 1987). In pre-synaptic terminals, BK channels 
limit the duration of calcium influx during APs, thereby decreasing neurotransmitter release (Griguoli et al., 2016; Yazejian et al., 2000). In muscles, BK channels regulate AP firing patterns, calcium influx during APs, and muscle contraction (Dopico et al., 2018; Latorre et al., 2017). Thus, Shank mutations could broadly alter neuron and muscle function via changes in $\mathrm{CaV}$-BK coupling. It will be very interesting to determine if this new function for Shank is conserved in other animals, including humans.

\section{SHN-1 promotes nanodomain coupling of CaV1 and BK channels. BK}

channel activation requires tight coupling to $\mathrm{CaV}$ channels (Berkefeld et al., 2006). Our results suggest that $\mathrm{SHN}-1$ promotes $\mathrm{CaV} 1-\mathrm{BK}$ nanodomain coupling. APs were

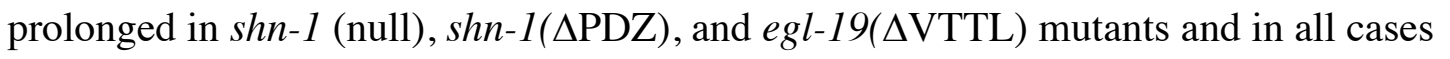
these defects were eliminated in double mutants lacking SLO-2. Interestingly, although all impair SLO-2 mediated AP repolarization, these mutations had distinct effects on SLO-2 channels. SLO-2 currents were reduced in shn-1 (null) and shn-1(DPDZ) mutants but were unaffected in egl-19( $\Delta$ VTTL) mutants. SLO-2 puncta intensity was decreased in

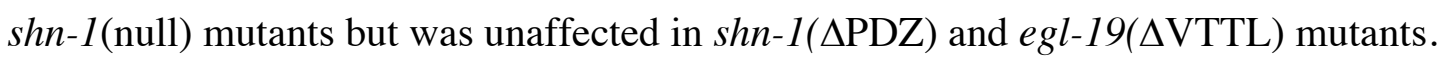
These differences suggest that these mutants comprise an allelic series for EGL-19 to SLO-2 coupling defects in the following hierarchy shn-1 (null)>shn-1( $\Delta \mathrm{PDZ})>$ egl$19(\Delta \mathrm{VTTL})$ mutants. Based on these results, we propose that multiple protein interactions progressively tighten $\mathrm{CaV}$-BK coupling. Specifically, we propose that: 1) multiple SHN-1 domains act together to promote SLO-2 coupling to EGL-19, accounting for the distinct phenotypes observed in shn-1(null) and shn-1( $\Delta \mathrm{PDZ})$ mutants; 2) SHN-1 promotes formation (or stability) of SLO-2 clusters in the plasma membrane, as indicated by decreased SLO-2 puncta intensity in shn-1(null) mutants; 3) beyond this trafficking 
function, SHN-1's PDZ domain tightens SLO-2 coupling to nearby calcium channels, accounting for the smaller SLO-2 current but unaltered SLO-2 puncta intensity in shn1( $\triangle \mathrm{PDZ})$ mutants; 4) SHN-1 PDZ binding to EGL-19's c-terminus promotes rapid SLO2 activation during APs, accounting for the increased AP width but unaltered SLO-2 current and puncta intensity in egl-19(AVTTL) mutants; and 5) SHN-1's PDZ must bind multiple proteins (not just EGL-19) to promote SLO-2 activation, accounting for the

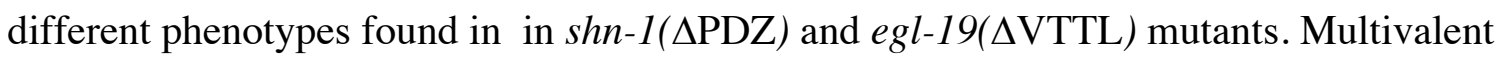
interactions between scaffolds and their client proteins may represent a general mechanism for promoting nanodomain signaling.

\section{Implications for understanding neurodevelopmental disorders. Shank3}

deletions and duplications both confer risk for ASD and schizophrenia (Bonaglia et al., 2006; Durand et al., 2007; Failla et al., 2007; Gauthier et al., 2010; Han et al., 2013). It is currently unclear how opposite changes in Shank3 levels produce similar psychiatric phenotypes. Different (potentially opposite) biochemical defects arising from decreased and increased Shank dosage could produce similar psychiatric traits, perhaps by circuit level mechanisms (Antoine et al., 2019; Peixoto et al., 2016). For example, Shank duplications and hemizygosity could act in different cells or circuits to produce similar psychiatric traits. Our results provide support for a second possibility. We find that increased and decreased shn-1 gene dosage produce similar cell autonomous CaV1-BK coupling defects. Two prior studies suggest that bidirectional changes in Shank produce similar defects in Wnt signaling and CaV1 current density (Harris et al., 2016; Pym et al., 2017). Collectively, these results suggest that some biochemical functions of Shank exhibit this unusual pattern of dose sensitivity and consequently could contribute to the pathophysiology of human Shankopathies (i.e. Shank3 mutations, CNVs, or PMS). 
The role of human Shank in CaV1-BK coupling has not been tested. Nonetheless, it seems plausible that this new physiological function could contribute to neuropsychiatric or co-morbid phenotypes associated with human Shankopathies. Consistent with this idea, PMS and human KCNMA1/BK mutations are associated with several shared phenotypes including: autism, developmental delay, intellectual disability, hypotonia, seizures, and gastrointestinal defects (i.e. vomiting, constipation, or diarrhea) (Bailey et al., 2019; Laumonnier et al., 2006; Phelan and McDermid, 2012; Soorya et al., 2013; Witmer et al., 2019). Moreover, BK channels are regulated by two high confidence ASD genes (UBE3A and hnRNP U). BK channels are degraded by the ubiquitin ligase UBE3A (Sun et al., 2019), mutations in which cause Angelman's syndrome. The RNA binding protein hnRNP U promotes translation of slo-2 mRNA (Liu et al., 2018). Collectively, these results support the idea that disrupted CaV1-BK channel coupling could play an important role in shankopathies and that BK channels may represent an important therapeutic target for treating these disorders. 


\section{Experimental Procedures:}

Strains: Strain maintenance and genetic manipulation were performed as described (Brenner, 1974). Animals were cultivated at room temperature $\left(\sim 22^{\circ} \mathrm{C}\right)$ on agar nematode growth media seeded with OP50 bacteria. Alleles used in this study are described in Table 2 and are identified in each figure legend. Transgenic animals were prepared by microinjection, and integrated transgenes were isolated following UV irradiation, as described (Dittman and Kaplan, 2006). Single copy transgenes were isolated by the MoSCI and miniMoS techniques (Frokjaer-Jensen et al., 2008; Frokjaer-Jensen et al., 2014).

\section{shn-1 dosage experiments:}

Animals with different shn-1 copy numbers were constructed as follows: 0 copies, shn1(nu712) homozygotes; 1 copy, unc-17::gfp (LX929) males were crossed with shn1(nu712) homozygotes and $g f p$-expressing hermaphrodites were analyzed; 2 copies, WT were analyzed; 4 copies, WT animals homozygous for the single copy transgene expressing SHN-1A in body muscles (nuSi26). The $n u S i 26$ transgene was described in our earlier study (Pym et al., 2017).

\section{CRISPR alleles}

CRISPR alleles were isolated as described (Arribere et al., 2014). Briefly, we used unc58 as a co-CRISPR selection to identify edited animals. Animals were injected with two guide RNAs (gRNAs) and two repair templates, one introducing an unc-58 gain of function mutation and a second modifying a gene of interest. Progeny exhibiting the unc$58(g f)$ uncoordinated phenotype were screened for successful editing of the second locus 
by PCR. Split GFP and split sfCherry constructs are described in (Feng et al., 2017). MiniMOS inserts in which Pmyo-3 drives expression of either GFP $_{1-10}$ (nuTi144) or sfCherry $1-10$ SL2 $_{\text {GFP }}$ 1-10 (nuTi458) were created.

Tissue specific shn-1 knockout was performed by introducing LoxP sites into intron 1 and the 3'UTR of the endogenous locus, in shn-1(nu697), and expressing CRE in muscles (pat-10 promoter) or neurons ( $s b t-1$ promoter). Tissue specific $s h n-1$ rescue was performed by introducing a stop cassette into intron 2 of shn- 1 using CRISPR, creating the shn-1(nu652) allele. The stop cassette consists of a synthetic exon (containing a consensus splice acceptor sequence and stop codons in all reading frames) followed by a 3' UTR and transcriptional terminator taken from the $f l p-28$ gene (the $564 \mathrm{bp}$ sequence just 3 ' to the $f l p-28$ stop codon). The stop cassette is flanked by FLEX sites (which are modified loxP sites that mediate CRE induced inversions) (Schnutgen and Ghyselinck, 2007). In this manner, orientation of the stop cassette within the shn-1 locus is controlled by CRE expression. Expression of $s h n-1$ is reduced when the stop cassette is in the OFF configuration (i.e. the same orientation as $s h n-1$ ) but is unaffected in the ON configuration (opposite orientation). The endogenous $f l p-28$ gene is located in an intron of W07E11.1 (in the opposite orientation). Consequently, we reasoned that the $f l p-28$ transcriptional terminator would interfere with shn-1 expression in an orientation selective manner. A similar strategy was previously described for conditional gene knockouts in Drosophila (Fisher et al., 2017).

\section{Fluorescence imaging}

Confocal imaging was performed using a Nikon 60x objective (NA 1.45) on a Nikon 
AR1 confocal microscope. Worms were immobilized on $10 \%$ agarose pads with $0.3 \mu 1$ of $0.1 \mu \mathrm{m}$ diameter polystyrene microspheres (Polysciences 00876-15, 2.5\% w/v suspension). Muscles just anterior to the vulva were imaged. For quantitation of florescence intensities, puncta were analyzed using Fiji.

\section{Electrophysiology}

Whole-cell patch-clamp measurements were performed using a Axopatch 200B amplifier with pClamp 10 software (Molecular Devices). The data were sampled at $10 \mathrm{kHz}$ and filtered at $5 \mathrm{kHz}$. All recordings were performed at room temperature $\left(\sim 19-21^{\circ} \mathrm{C}\right)$

Muscle APs- The bath solution contained (in $\mathrm{mM}$ ): $\mathrm{NaCl} 140, \mathrm{KCl} 5, \mathrm{CaCl}_{2} 5, \mathrm{MgCl}_{2}$ 5, dextrose 11 and HEPES 5 (pH 7.2, $320 \mathrm{mOsm}$ ). The pipette solution contained (in $\mathrm{mM}$ ): Kgluconate 120, $\mathrm{KOH} 20$, Tris 5, $\mathrm{CaCl}_{2}$ 0.25, $\mathrm{MgCl}_{2}$ 4, sucrose 36, EGTA 5 (or BAPTA 5), and $\mathrm{Na}_{2} \mathrm{ATP} 4$ (pH 7.2, $323 \mathrm{mOsm}$ ). Spontaneous APs were recorded in currentclamp without current injection. Cell resistance $\left(R_{\text {in }}\right)$ was measured following a $10 \mathrm{pA}$ pulse injection. AP traces were analyzed in Matlab. APs were defined as depolarizations lasting $<150 \mathrm{~ms}$. PPs were defined as depolarizations lasting $>150 \mathrm{~ms}$.

$K^{+}$current recordings - The bath solution contained (in $\mathrm{mM}$ ): $\mathrm{NaCl} 140, \mathrm{KCl} 5, \mathrm{CaCl}_{2} 5$, $\mathrm{MgCl}_{2}$ 5, dextrose 11 and HEPES 5 (pH 7.2, 320 mOsm). For $\mathrm{Ik}_{\mathrm{loCl}}$ recordings, the pipette solution contained (in $\mathrm{mM}$ ): Kgluconate $120, \mathrm{KOH} 20$, Tris 5, $\mathrm{CaCl}_{2}$ 0.25, $\mathrm{MgCl}_{2}$ 4, sucrose 36, EGTA 5 and Na2ATP 4 (pH 7.2, 323 mOsm). For $\mathrm{Ik}_{\mathrm{hiCl}}$ recordings, the pipette solution contained (in $\mathrm{mM}$ ): $\mathrm{KCl} 120, \mathrm{KOH} 20$, Tris 5, $\mathrm{CaCl}_{2} 0.25, \mathrm{MgCl}_{2} 4$, sucrose 36, EGTA 5 (or BAPTA 5), and $\mathrm{Na}_{2} \mathrm{ATP} 4$ (pH 7.2, 323 mOsm). The voltage- 
clamp protocol consisted of $-60 \mathrm{mV}$ for $50 \mathrm{~ms},-90 \mathrm{mV}$ for $50 \mathrm{~ms}$, test voltage (from -

$60 \mathrm{mV}$ to $+60 \mathrm{mV}$ ) $150 \mathrm{~ms}$. The repetitive stimulus protocol was $-20 \mathrm{mV}$ for $50 \mathrm{~ms},+30 \mathrm{mV}$

for 50ms, which was repeated 20 times. In figures, we show outward currents evoked at $+30 \mathrm{mV}$, which corresponds to the peak amplitude of muscle APs. In some recordings, EGL-19 channels were blocked by adding $5 \mu \mathrm{M}$ nemadipine to the pipette solution. Patch clamp recording of $\mathrm{Ik}_{\mathrm{hiCl}}$ in $\mathrm{ACh}$ motor neurons was done using solutions described above for the muscle recordings. ACh neurons were identified for patching by expression of unc-17 VAChT $>$ GFP.

\section{Statistical methods}

For normally distributed data, significant differences were assessed with unpaired t tests (for 2 groups) or one way ANOVA with post-hoc Dunn's multiple comparisons test (for $>2$ groups). For non-normal data, differences were assessed by Mann-Whitney (2 groups) or Kruskal-Wallis test with post-hoc Dunn's multiple comparisons test ( $>2$ groups). Data graphing and statistics were performed in GraphPad Prism 9. No statistical method was used to select sample sizes. Data shown in each figure represent contemporaneous measurements from mutant and control animals over a period of 1-2 weeks. For electrophysiology, data points represent mean values for individual neuron or muscle recordings (which were considered biological replicates). For imaging studies, data points represent mean puncta fluorescence values in individual animals (which were considered biological replicates). All data obtained in each experiment were analyzed, without any exclusions.

\section{Acknowledgements}


We thank the following for strains, advice, reagents, and comments on the manuscript: $C$.

elegans stock center, S. Mitani, and members of the Kaplan lab. This work was supported

by an NIH research grant to J.K. (NS32196). 


\section{Figure Legends:}

Figure 1. SHN-1 regulates muscle AP firing patterns. (A) Representative traces of spontaneous muscle APs are shown for WT and shn-1(nu712) null mutants. APs occur in bursts of $\sim 10$ APs/ burst. Plateau potentials (PPs), defined as transients lasting $>150 \mathrm{ms,}$ are observed less frequently, often at the end of a burst. (B) APs become progressively longer during bursts. Successive APs taken from a representative burst are shown. (C) Repetitive depolarization to $+30 \mathrm{mV}$ leads to a progressive decrease in potassium currents. A representative recording from a WT animal is shown. This likely results from an accumulation of inactivated potassium channels during repetitive stimulation. (D-I) Mean PP rate (D), AP rate (E), AP width (F), RMP (G), AP amplitude (H), and input resistance $\left(\mathrm{R}_{\mathrm{in}}, \mathrm{I}\right)$ are compared in WT and shn-1 null mutants. All shn-1 data were obtained from shn-1(nu712) except for $\mathrm{R}_{\text {in }}(\mathrm{I})$, which were from shn-1(tm488). Values that differ significantly from wild type controls are indicated (ns, not significant; ${ }^{*}, p$ $<0.05 ; * *, p<0.01 ; * * *, p<0.001)$. Error bars indicate SEM.

Figure 1, Supplement 1. SHN-1 is expressed in many tissues. Endogenous SHN-1 is broadly expressed, including in neurons, muscles, skin, and glia. A representative image of reconstituted fluorescence produced by $s h n-1$ (nu600 GFP $\left.{ }_{11}\right)$ and eft-3>GFP $\mathrm{G}_{1-10}$ (left) and the corresponding bright field image (right) are shown. Scale bar indicates $14 \mu \mathrm{m}$.

\section{Figure 2. SHN-1 acts in muscles to control AP duration.}

(A) A schematic of the shn-1 locus is shown. Open boxes indicate UTRs, black boxes indicate coding regions. Recombination sites mediating CRE induced deletions (LoxP) 
and inversions (FLEX) are indicated. The shn-1(nu697) allele allows CRE induced shn-1 knockouts while shn-1(nu652) allows CRE induced shn-1 rescue. In shn-1(nu652), an exon containing in frame stop codons was inserted into the second intron (in the "OFF" orientation). This stop exon is bounded by FLEX sites. (B) Representative traces of spontaneous muscle APs are shown in shn-1(nu697) with and without muscle CRE expression. Mean PP rate (C) and AP width (D) are compared in the indicated shn-1 mutants without (-) and with CRE expression in muscles (m) or neurons (n). Values that differ significantly from wild type controls are indicated (ns, not significant; ${ }^{*}, p<0.05$; $* *, p<0.01 ; * * *, p<0.001)$. Error bars indicate SEM.

\section{Figure 3. Mutations disrupting SHN-1 binding to EGL-19 increase AP duration.}

(A) A schematic illustrating the binding interaction between EGL-19's c-terminus and SHN-1's PDZ domain is shown. (B-C) Mean PP rate and AP width are compared in the indicated genotypes. Mutations deleting the SHN-1 PDZ domain (nu542 $\triangle \mathrm{PDZ}$ ) or those deleting EGL-19's c-terminal PDZ ligand (nu496 $\Delta$ VTTL) were edited into the endogenous genes using CRISPR. These mutations significantly increased AP width, compared to WT controls. Values that differ significantly from wild type controls are indicated (ns, not significant; $*, p<0.05 ; * *, p<0.01 ; * * *, p<0.001$ ). Error bars indicate SEM.

Figure 4. AP repolarization is mediated by SHK-1 and SLO-2 channels.

(A-D) Muscle voltage activated potassium currents are mediated by SHK-1 and SLO-2. Voltage activated potassium currents were recorded using pipette solutions containing low ( $\left.\mathrm{Ik}_{\mathrm{loCl}}, \mathrm{A}-\mathrm{B}\right)$ and high $\left(\mathrm{Ik}_{\mathrm{hiCl}}, \mathrm{C}-\mathrm{D}\right)$ chloride concentrations. Representative traces 
$(\mathrm{A}, \mathrm{C})$ and mean current density $(\mathrm{B}, \mathrm{D})$ at $+30 \mathrm{mV}$ are shown. $\mathrm{Ik}_{\mathrm{loCl}}$ is mediated by $\mathrm{SHK}-1$ whereas SHK-1 and SLO-2 equally contribute to $\mathrm{Ik}_{\text {hicl }}$ (E-F) AP durations are significantly increased in mutants lacking SHK-1, SLO-1, and SLO-2 channels. The AP widths observed in slo-1; slo-2 double mutants were not significantly different from those found in slo-2 single mutants. Representative traces (E) and mean AP widths (F) are shown. Alleles used in this figure were: shk-1(ok1581), slo-1(js379), and slo-2(nf100). Values that differ significantly from wild type controls are indicated (ns, not significant; $*, p<0.05 ; * *, p<0.01 ; * * *, p<0.001)$. Error bars indicate SEM.

Figure 5. SLO-2 and SLO-1 function together in heteromeric channels. (A-B) $\mathrm{Ik}_{\mathrm{hiCl}}$ was significantly decreased in slo-1(js379) and slo-2(nf100) single mutants but was not further decreased in slo-1; slo-2 double mutants. Representative traces (A) and mean current density (B) at $+30 \mathrm{mV}$ are shown. (C-F) Expression of split GFP tagged SLO-2 (C-D) and SLO-1 (E-F) was analyzed in body muscles. CRISPR alleles were constructed adding 7 copies of $\mathrm{GFP}_{11}$ to the endogenous slo- 1 and slo-2 genes (Table 2) and fluorescence was reconstituted by expressing $\mathrm{GFP}_{1-10}$ in body muscles. Controls showing that the GFP ${ }_{11}$ tags had no effect on AP width, RMP, and potassium currents are shown in Figure 5 supplement 1. Representative images (C and $\mathrm{E})$ and mean puncta intensity (D and F) are shown. SLO-2 puncta intensity was significantly decreased in slo-1(js379) mutants. SLO-1 puncta intensity was unaltered in slo-2(nf100) mutants. Values that differ significantly from wild type controls are indicated (ns, not significant; ${ }^{*}, p<0.05 ;{ }^{*}, p$ $<0.01 ; * * *, p<0.001)$. Error bars indicate SEM. Scale bar indicates $4 \mu \mathrm{m}$. 
Figure 5. Supplement 1. Analysis of GFP 11 tagged slo-1 and slo-2 alleles. APs and potassium currents were analyzed in strains containing slo-1(nu678 $\left.\mathrm{GFP}_{11}\right)$ and slo2(nu725 $\left.\mathrm{GFP}_{11}\right)$ together with the muscle $>\mathrm{GFP}_{1-10}$ transgene. Mean AP width (A), RMP (B), and Ik $\mathrm{k}_{\mathrm{hiCl}}$ current density (C) were not significantly different from WT controls. Error bars indicate SEM.

Figure 6. SHN-1 controls AP width by regulating SLO-2. (A) A slo-2 null mutation blocks the effect of SHN-1 on AP width. Mean AP widths in slo-2(nf100) double mutants containing shn-1(nu712 null), shn-1(nu542 $\Delta \mathrm{PDZ})$, and egl-19(nu496 $\Delta \mathrm{VTTL})$ mutations were not significantly different from those in slo- 2 single mutants. (B-C) $\mathrm{Ik}_{\mathrm{loCl}}$ currents were unaltered in shn-1(nu712 null) mutants. Representative traces (B) and mean current density at $+30 \mathrm{mV}(\mathrm{C})$ are shown. These results show that the function of SHK-1 channels was unaffected in shn-1 mutants. (D-E) $\mathrm{Ik}_{\mathrm{hiCl}}$ currents were significantly smaller in shn-1(nu712 null) and shn-1(nu542 $\Delta \mathrm{PDZ})$ mutants but were unaffected in egl19 (nu496 $\Delta$ VTTL) mutants. The effect of $s h n-1$ mutations on $\mathrm{Ik}_{\mathrm{hiCl}}$ was eliminated in double mutants lacking SLO-2, indicating that the $\mathrm{SHN}-1$ sensitive potassium current is mediated by SLO-2. I $\mathrm{k}_{\mathrm{hiCl}}$ currents were recorded from adult body wall muscles of the indicated genotypes at holding potentials of -60 to $+60 \mathrm{mV}$. Representative traces (D) and mean current density at $+30 \mathrm{mV}(\mathrm{E})$ are shown. Values that differ significantly from wild type controls are indicated (ns, not significant; *, $p<0.05 ; * *, p<0.01 ; * * *, p<0.001$ ). Error bars indicate SEM.

Figure 7. SHN-1 promotes EGL-19 to SLO-2 nanodomain coupling. (A-B) SLO-2 activation is functionally coupled to EGL-19. I $\mathrm{k}_{\mathrm{hiCl}}$ was significantly reduced by 
nemadapine (an EGL-19 antagonist). This inhibitory effect of nemadopine on $\mathrm{Ik}_{\mathrm{hiCl}}$ was eliminated in slo-2(nf100) mutants, indicating that the nemadapine sensitive current is mediated by SLO-2. Ik $\mathrm{k}_{\mathrm{hiCl}}$ currents were recorded from adult body wall muscles of the indicated genotypes at holding potentials of -60 to $+60 \mathrm{mV}$. Representative $\mathrm{Ik}_{\mathrm{hiCl}}$ traces (A) and mean current density as a function of membrane potential (B) are shown. (C) SLO-2 activation requires nanodomain coupling to EGL-19. $\mathrm{Ik}_{\mathrm{hiCl}}$ currents recorded in BAPTA are significantly smaller than those in EGTA. The inhibitory effect of BAPTA was reduced in shn-1(nu712 null) mutants and was eliminated in slo-2(nf100) mutants, indicating that the BAPTA sensitive current is mediated by SLO-2. The ratio of $\mathrm{Ik}_{\mathrm{hiCl}}$ current density at $+30 \mathrm{mV}$ recorded in BAPTA to the mean current density recorded in EGTA is plotted for the indicated genotypes. (D-E) AP repolarization is mediated by nanodomain activation of SLO-2. AP widths recorded in solutions containing BAPTA are wider than those recorded in EGTA. The effect of BAPTA on AP widths was reduced in shn-1(nu712 null) mutants and was eliminated in slo-2(nf100) mutants, indicating that BAPTA's effect is mediated by SLO-2. Representative traces of WT muscle APs recorded in EGTA and BAPTA are shown (D). The ratio of AP widths recorded in BAPTA to the mean AP widths recorded in EGTA is plotted for the indicated genotypes (E). (F-G) SLO-2(nu725 GFP S11 $_{11}$ is partially co-localized with EGL-19(nu722 Cherry 11 ) in body muscles. GFP and Cherry fluorescence were reconstituted with $\mathrm{GFP}_{1-10}$ and Cherry $1-10$ expressed in body muscles. SLO-2 puncta intensity was significantly reduced in shn-1(nu712 null) mutants but was unaffected in shn-1(nu542 $\Delta \mathrm{PDZ})$ and egl19(nu496 $\Delta$ VTTL) mutants. Representative images (F) and mean SLO-2 puncta intensity (G) are shown. Values that differ significantly from wild type controls are indicated (ns, 
not significant; $\left.{ }^{*}, p<0.05 ; * *, p<0.01 ; * * *, p<0.001\right)$. Error bars indicate SEM. Scale bar indicates $4 \mu \mathrm{m}$.

\section{Figure 7. Supplement 1. SLO-1 puncta intensity is unaltered in shn-1 mutant}

muscles. SLO-1(nu678 $\left.\mathrm{GFP}_{11}\right)$ puncta intensity in body muscles is compared in WT and shn-1(nu712 null) mutants. Representative images (A) and mean SLO-2 puncta intensity (B) are shown. Values that differ significantly from wild type controls are indicated (ns, not significant; *, $p<0.05 ; * *, p<0.01 ; * * *, p<0.001)$. Error bars indicate SEM.

Figure 8. AP width and SLO-2 current are sensitive to shn-1 gene dosage. The effect of shn-1 gene dosage on AP widths (A-B) and $\mathrm{Ik}_{\mathrm{hiCl}}$ current (C-D) was analyzed. $\mathrm{Ik}_{\mathrm{hiCl}}$ was significantly decreased while AP duration was significantly increased in animals containing 1 and 4 copies of shn- 1 compared to WT controls (i.e. 2 copies). The following genotypes were analyzed: 1 copy of $\operatorname{shn}-1$ [shn-1(nu712)/+ heterozygotes], 2 copies of $s h n-1$ (WT) and 4 copies of $s h n-1$ (nuSi26 homozygotes in wild-type). Ik $\mathrm{kiCl}_{\mathrm{hi}}$ currents were recorded from adult body wall muscles of the indicated genotypes at holding potentials of -60 to $+60 \mathrm{mV}$. Representative traces (A,C), mean AP width (B), and mean $\mathrm{Ik}_{\mathrm{hiCl}}$ current density at $+30 \mathrm{mV}$ (D) are shown. Significant differences are indicated (ns, not significant; ${ }^{*}, p<0.05 ; * *, p<0.01 ; * * *, p<0.001$ ). Error bars indicate SEM.

Figure 9. SHN-1 controls SLO-2 currents in motor neurons. (A-B) I $\mathrm{k}_{h i C l}$ currents in cholinergic motor neurons were significantly decreased in shn-1(nu712 null) mutants. I $\mathrm{k}_{\mathrm{hiCl}}$ currents were recorded from adult cholinergic motor neurons of the indicated 
genotypes at holding potentials of -60 to $+60 \mathrm{mV}$. Representative traces (A), mean current density as a function of membrane potential (B), and mean current density at +30 $\mathrm{mV}(\mathrm{C})$ are shown. (D-E) SLO-2 puncta intensity in motor neuron axons was significantly decreased in shn-1(nu712 null) mutants. Representative images of SLO2(nu725 GFP 11$)$ and a synaptic vesicle marker [UNC-57/Endophilin(mCherry)] in dorsal cord axons of DA/DB motor neurons are shown (D). GFP $_{11}$ fluorescence was reconstituted with $\mathrm{GFP}_{1-10}$ expressed in $\mathrm{DA} / \mathrm{DB}$ motor neurons (using the unc-129 promoter). Mean SLO-2 puncta intensity in axons is plotted (E). Values that differ significantly from wild type controls are indicated (ns, not significant; ${ }^{*}, p<0.05 ; * *, p$ $<0.01 ; * * *, p<0.001)$. Error bars indicate SEM. Scale bar indicates $2 \mu \mathrm{m}$. 


\section{References:}

Adams, P.R., Constanti, A., Brown, D.A., and Clark, R.B. (1982). Intracellular Ca2+ activates a fast voltage-sensitive $\mathrm{K}+$ current in vertebrate sympathetic neurones. Nature 296, 746-749.

Antoine, M.W., Langberg, T., Schnepel, P., and Feldman, D.E. (2019). Increased Excitation-Inhibition Ratio Stabilizes Synapse and Circuit Excitability in Four Autism Mouse Models. Neuron 101, 648-661 e644.

Arribere, J.A., Bell, R.T., Fu, B.X., Artiles, K.L., Hartman, P.S., and Fire, A.Z. (2014). Efficient marker-free recovery of custom genetic modifications with CRISPR/Cas9 in Caenorhabditis elegans. Genetics 198, 837-846.

Bailey, C.S., Moldenhauer, H.J., Park, S.M., Keros, S., and Meredith, A.L. (2019). KCNMA1-linked channelopathy. J Gen Physiol 151, 1173-1189.

Barrett, J.N., Magleby, K.L., and Pallotta, B.S. (1982). Properties of single calciumactivated potassium channels in cultured rat muscle. J Physiol 331, 211-230.

Berkefeld, H., Sailer, C.A., Bildl, W., Rohde, V., Thumfart, J.O., Eble, S., Klugbauer, N., Reisinger, E., Bischofberger, J., Oliver, D., et al. (2006). BKCa-Cav channel complexes mediate rapid and localized $\mathrm{Ca} 2+$-activated $\mathrm{K}+$ signaling. Science 314, 615-620.

Bonaglia, M.C., Giorda, R., Beri, S., De Agostini, C., Novara, F., Fichera, M., Grillo, L., Galesi, O., Vetro, A., Ciccone, R., et al. (2011). Molecular mechanisms generating and stabilizing terminal 22q13 deletions in 44 subjects with Phelan/McDermid syndrome. PLoS Genet 7, e1002173.

Bonaglia, M.C., Giorda, R., Mani, E., Aceti, G., Anderlid, B.M., Baroncini, A., Pramparo, T., and Zuffardi, O. (2006). Identification of a recurrent breakpoint within the SHANK3 gene in the 22q13.3 deletion syndrome. Journal of medical genetics 43, 822828.

Brenner, S. (1974). The genetics of Caenorhabditis elegans. Genetics 77, 71-94.

Cao, J., Packer, J.S., Ramani, V., Cusanovich, D.A., Huynh, C., Daza, R., Qiu, X., Lee, C., Furlan, S.N., Steemers, F.J., et al. (2017). Comprehensive single-cell transcriptional profiling of a multicellular organism. Science 357, 661-667.

Chen, H., Kronengold, J., Yan, Y., Gazula, V.R., Brown, M.R., Ma, L., Ferreira, G., Yang, Y., Bhattacharjee, A., Sigworth, F.J., et al. (2009). The N-terminal domain of Slack determines the formation and trafficking of Slick/Slack heteromeric sodiumactivated potassium channels. J Neurosci 29, 5654-5665. 
Contreras, G.F., Castillo, K., Enrique, N., Carrasquel-Ursulaez, W., Castillo, J.P., Milesi, V., Neely, A., Alvarez, O., Ferreira, G., Gonzalez, C., et al. (2013). A BK (Slo1) channel journey from molecule to physiology. Channels (Austin) 7, 442-458.

Cross-Disorder Group of the Psychiatric Genomics, C. (2013). Identification of risk loci with shared effects on five major psychiatric disorders: a genome-wide analysis. Lancet $381,1371-1379$.

Dittman, J.S., and Kaplan, J.M. (2006). Factors regulating the abundance and localization of synaptobrevin in the plasma membrane. Proc Natl Acad Sci U S A 103, 11399-11404.

Dopico, A.M., Bukiya, A.N., and Jaggar, J.H. (2018). Calcium- and voltage-gated BK channels in vascular smooth muscle. Pflugers Arch 470, 1271-1289.

Durand, C.M., Betancur, C., Boeckers, T.M., Bockmann, J., Chaste, P., Fauchereau, F., Nygren, G., Rastam, M., Gillberg, I.C., Anckarsater, H., et al. (2007). Mutations in the gene encoding the synaptic scaffolding protein SHANK3 are associated with autism spectrum disorders. Nat Genet 39, 25-27.

Edgerton, J.R., and Reinhart, P.H. (2003). Distinct contributions of small and large conductance $\mathrm{Ca} 2+$-activated $\mathrm{K}+$ channels to rat Purkinje neuron function. J Physiol 548, 53-69.

Failla, P., Romano, C., Alberti, A., Vasta, A., Buono, S., Castiglia, L., Luciano, D., Di Benedetto, D., Fichera, M., and Galesi, O. (2007). Schizophrenia in a patient with subtelomeric duplication of chromosome 22q. Clin Genet 71, 599-601.

Feng, S., Sekine, S., Pessino, V., Li, H., Leonetti, M.D., and Huang, B. (2017). Improved split fluorescent proteins for endogenous protein labeling. Nat Commun 8,370 .

Fisher, Y.E., Yang, H.H., Isaacman-Beck, J., Xie, M., Gohl, D.M., and Clandinin, T.R. (2017). FlpStop, a tool for conditional gene control in Drosophila. Elife 6.

Frokjaer-Jensen, C., Davis, M.W., Hopkins, C.E., Newman, B.J., Thummel, J.M., Olesen, S.P., Grunnet, M., and Jorgensen, E.M. (2008). Single-copy insertion of transgenes in Caenorhabditis elegans. Nat Genet 40, 1375-1383.

Frokjaer-Jensen, C., Davis, M.W., Sarov, M., Taylor, J., Flibotte, S., LaBella, M., Pozniakovsky, A., Moerman, D.G., and Jorgensen, E.M. (2014). Random and targeted transgene insertion in Caenorhabditis elegans using a modified Mos1 transposon. Nat Methods 11, 529-534.

Gao, S., and Zhen, M. (2011). Action potentials drive body wall muscle contractions in Caenorhabditis elegans. Proc Natl Acad Sci U S A 108, 2557-2562. 
Gauthier, J., Champagne, N., Lafreniere, R.G., Xiong, L., Spiegelman, D., Brustein, E., Lapointe, M., Peng, H., Cote, M., Noreau, A., et al. (2010). De novo mutations in the gene encoding the synaptic scaffolding protein SHANK3 in patients ascertained for schizophrenia. Proc Natl Acad Sci U S A 107, 7863-7868.

Geiger, J.R., and Jonas, P. (2000). Dynamic control of presynaptic $\mathrm{Ca}(2+)$ inflow by fastinactivating $\mathrm{K}(+)$ channels in hippocampal mossy fiber boutons. Neuron 28, 927-939.

Golding, N.L., Jung, H.Y., Mickus, T., and Spruston, N. (1999). Dendritic calcium spike initiation and repolarization are controlled by distinct potassium channel subtypes in CA1 pyramidal neurons. J Neurosci 19, 8789-8798.

Grabrucker, A.M., Schmeisser, M.J., Schoen, M., and Boeckers, T.M. (2011). Postsynaptic ProSAP/Shank scaffolds in the cross-hair of synaptopathies. Trends Cell Biol 21, 594-603.

Griguoli, M., Sgritta, M., and Cherubini, E. (2016). Presynaptic BK channels control transmitter release: physiological relevance and potential therapeutic implications. J Physiol 594, 3489-3500.

Han, K., Holder, J.L., Jr., Schaaf, C.P., Lu, H., Chen, H., Kang, H., Tang, J., Wu, Z., Hao, S., Cheung, S.W., et al. (2013). SHANK3 overexpression causes manic-like behaviour with unique pharmacogenetic properties. Nature 503, 72-77.

Han, Q., Kim, Y.H., Wang, X., Liu, D., Zhang, Z.J., Bey, A.L., Lay, M., Chang, W., Berta, T., Zhang, Y., et al. (2016). SHANK3 Deficiency Impairs Heat Hyperalgesia and TRPV1 Signaling in Primary Sensory Neurons. Neuron 92, 1279-1293.

Harris, K.P., Akbergenova, Y., Cho, R.W., Baas-Thomas, M.S., and Littleton, J.T. (2016). Shank Modulates Postsynaptic Wnt Signaling to Regulate Synaptic Development. J Neurosci 36, 5820-5832.

Ingiosi, A.M., Schoch, H., Wintler, T., Singletary, K.G., Righelli, D., Roser, L.G., Medina, E., Risso, D., Frank, M.G., and Peixoto, L. (2019). Shank3 modulates sleep and expression of circadian transcription factors. Elife 8.

Jackson, M.B., Konnerth, A., and Augustine, G.J. (1991). Action potential broadening and frequency-dependent facilitation of calcium signals in pituitary nerve terminals. Proc Natl Acad Sci U S A 88, 380-384.

Jiang, Y.H., and Ehlers, M.D. (2013). Modeling autism by SHANK gene mutations in mice. Neuron 78, 8-27. 
Jospin, M., Jacquemond, V., Mariol, M.C., Segalat, L., and Allard, B. (2002). The L-type voltage-dependent $\mathrm{Ca} 2+$ channel EGL-19 controls body wall muscle function in Caenorhabditis elegans. J Cell Biol 159, 337-348.

Kim, H., Pierce-Shimomura, J.T., Oh, H.J., Johnson, B.E., Goodman, M.B., and McIntire, S.L. (2009). The dystrophin complex controls bk channel localization and muscle activity in Caenorhabditis elegans. PLoS Genet 5, e1000780.

Kole, M.H., Letzkus, J.J., and Stuart, G.J. (2007). Axon initial segment Kv1 channels control axonal action potential waveform and synaptic efficacy. Neuron 55, 633-647.

Kwok, T.C., Hui, K., Kostelecki, W., Ricker, N., Selman, G., Feng, Z.P., and Roy, P.J. (2008). A genetic screen for dihydropyridine (DHP)-resistant worms reveals new residues required for DHP-blockage of mammalian calcium channels. PLoS Genetics 4, e1000067.

Latorre, R., Castillo, K., Carrasquel-Ursulaez, W., Sepulveda, R.V., Gonzalez-Nilo, F., Gonzalez, C., and Alvarez, O. (2017). Molecular Determinants of BK Channel Functional Diversity and Functioning. Physiol Rev 97, 39-87.

Laumonnier, F., Roger, S., Guerin, P., Molinari, F., M'Rad, R., Cahard, D., Belhadj, A., Halayem, M., Persico, A.M., Elia, M., et al. (2006). Association of a functional deficit of the BKCa channel, a synaptic regulator of neuronal excitability, with autism and mental retardation. Am J Psychiatry 163, 1622-1629.

Lee, J.H., Park, H., Park, S.J., Kim, H.J., and Eom, S.H. (2011). The structural flexibility of the shank1 PDZ domain is important for its binding to different ligands. Biochem Biophys Res Commun 407, 207-212.

Lilja, J., Zacharchenko, T., Georgiadou, M., Jacquemet, G., De Franceschi, N., Peuhu, E., Hamidi, H., Pouwels, J., Martens, V., Nia, F.H., et al. (2017). SHANK proteins limit integrin activation by directly interacting with Rap1 and R-Ras. Nat Cell Biol 19, 292305.

Liu, P., Chen, B., and Wang, Z.W. (2014). SLO-2 potassium channel is an important regulator of neurotransmitter release in Caenorhabditis elegans. Nat Commun 5, 5155.

Liu, P., Ge, Q., Chen, B., Salkoff, L., Kotlikoff, M.I., and Wang, Z.W. (2011). Genetic dissection of ion currents underlying all-or-none action potentials in C. elegans body-wall muscle cells. J Physiol 589, 101-117.

Liu, P., Wang, S.J., Wang, Z.W., and Chen, B. (2018). HRPU-2, a Homolog of Mammalian hnRNP U, Regulates Synaptic Transmission by Controlling the Expression of SLO-2 Potassium Channel in Caenorhabditis elegans. J Neurosci 38, 1073-1084. 
Liu, Q., Chen, B., Ge, Q., and Wang, Z.W. (2007). Presynaptic Ca2+/calmodulindependent protein kinase II modulates neurotransmitter release by activating BK channels at Caenorhabditis elegans neuromuscular junction. J Neurosci 27, 10404-10413.

Oh, W.C., Song, H.O., Cho, J.H., and Park, B.J. (2011). ANK repeat-domain of SHN-1 Is indispensable for in vivo SHN-1 function in C. elegans. Mol Cells 31, 79-84.

Packer, J.S., Zhu, Q., Huynh, C., Sivaramakrishnan, P., Preston, E., Dueck, H., Stefanik, D., Tan, K., Trapnell, C., Kim, J., et al. (2019). A lineage-resolved molecular atlas of C. elegans embryogenesis at single-cell resolution. Science 365.

Peca, J., Feliciano, C., Ting, J.T., Wang, W., Wells, M.F., Venkatraman, T.N., Lascola, C.D., Fu, Z., and Feng, G. (2011). Shank3 mutant mice display autistic-like behaviours and striatal dysfunction. Nature 472, 437-442.

Peixoto, R.T., Wang, W., Croney, D.M., Kozorovitskiy, Y., and Sabatini, B.L. (2016). Early hyperactivity and precocious maturation of corticostriatal circuits in Shank3B(-/-) mice. Nat Neurosci 19, 716-724.

Perfitt, T.L., Wang, X., Dickerson, M.T., Stephenson, J.R., Nakagawa, T., Jacobson, D.A., and Colbran, R.J. (2020). Neuronal L-Type Calcium Channel Signaling to the Nucleus Requires a Novel CaMKIIalpha-Shank3 Interaction. J Neurosci 40, 2000-2014.

Petersen, O.H., and Maruyama, Y. (1984). Calcium-activated potassium channels and their role in secretion. Nature 307, 693-696.

Phelan, K., and McDermid, H.E. (2012). The 22q13.3 Deletion Syndrome (PhelanMcDermid Syndrome). Mol Syndromol 2, 186-201.

Pym, E., Sasidharan, N., Thompson-Peer, K.L., Simon, D.J., Anselmo, A., Sadreyev, R., Hall, Q., Nurrish, S., and Kaplan, J.M. (2017). Shank is a dose-dependent regulator of Cav1 calcium current and CREB target expression. Elife 6.

Sakai, Y., Shaw, C.A., Dawson, B.C., Dugas, D.V., Al-Mohtaseb, Z., Hill, D.E., and Zoghbi, H.Y. (2011). Protein interactome reveals converging molecular pathways among autism disorders. Sci Transl Med 3, 86ra49.

Sancar, F., Touroutine, D., Gao, S., Oh, H.J., Gendrel, M., Bessereau, J.L., Kim, H., Zhen, M., and Richmond, J.E. (2011). The dystrophin-associated protein complex maintains muscle excitability by regulating $\mathrm{Ca}(2+)$-dependent $\mathrm{K}(+)(\mathrm{BK})$ channel localization. J Biol Chem 286, 33501-33510. 
Santi, C.M., Yuan, A., Fawcett, G., Wang, Z.W., Butler, A., Nonet, M.L., Wei, A., Rojas, P., and Salkoff, L. (2003). Dissection of K+ currents in Caenorhabditis elegans muscle cells by genetics and RNA interference. Proc Natl Acad Sci U S A 100, 14391-14396.

Schnutgen, F., and Ghyselinck, N.B. (2007). Adopting the good reFLEXes when generating conditional alterations in the mouse genome. Transgenic Res 16, 405-413.

Soorya, L., Kolevzon, A., Zweifach, J., Lim, T., Dobry, Y., Schwartz, L., Frank, Y., Wang, A.T., Cai, G., Parkhomenko, E., et al. (2013). Prospective investigation of autism and genotype-phenotype correlations in 22q13 deletion syndrome and SHANK3 deficiency. Mol Autism 4, 18.

Speed, H.E., Kouser, M., Xuan, Z., Liu, S., Duong, A., and Powell, C.M. (2019). Apparent Genetic Rescue of Adult Shank3 Exon 21 Insertion Mutation Mice Tempered by Appropriate Control Experiments. eNeuro 6.

Splawski, I., Timothy, K.W., Decher, N., Kumar, P., Sachse, F.B., Beggs, A.H., Sanguinetti, M.C., and Keating, M.T. (2005). Severe arrhythmia disorder caused by cardiac L-type calcium channel mutations. Proc Natl Acad Sci U S A 102, 8089-8096; discussion 8086-8088.

Splawski, I., Timothy, K.W., Sharpe, L.M., Decher, N., Kumar, P., Bloise, R., Napolitano, C., Schwartz, P.J., Joseph, R.M., Condouris, K., et al. (2004). Ca(V)1.2 calcium channel dysfunction causes a multisystem disorder including arrhythmia and autism. Cell 119, 19-31.

Storm, J.F. (1987). Action potential repolarization and a fast after-hyperpolarization in rat hippocampal pyramidal cells. J Physiol 385, 733-759.

Sun, A.X., Yuan, Q., Fukuda, M., Yu, W., Yan, H., Lim, G.G.Y., Nai, M.H., D'Agostino, G.A., Tran, H.D., Itahana, Y., et al. (2019). Potassium channel dysfunction in human neuronal models of Angelman syndrome. Science 366, 1486-1492.

Tatavarty, V., Torrado Pacheco, A., Groves Kuhnle, C., Lin, H., Koundinya, P., Miska, N.J., Hengen, K.B., Wagner, F.F., Van Hooser, S.D., and Turrigiano, G.G. (2020). Autism-Associated Shank3 Is Essential for Homeostatic Compensation in Rodent V1. Neuron 106, 769-777 e764.

Wang, W., Li, C., Chen, Q., van der Goes, M.S., Hawrot, J., Yao, A.Y., Gao, X., Lu, C., Zang, Y., Zhang, Q., et al. (2017). Striatopallidal dysfunction underlies repetitive behavior in Shank3-deficient model of autism. The Journal of clinical investigation 127, 1978-1990. 
Wang, Z.W., Saifee, O., Nonet, M.L., and Salkoff, L. (2001). SLO-1 potassium channels control quantal content of neurotransmitter release at the $\mathrm{C}$. elegans neuromuscular junction. Neuron 32, 867-881.

Witmer, C., Mattingly, A., D'Souza, P., Thurm, A., and Hadigan, C. (2019). Incontinence in Phelan-McDermid Syndrome. J Pediatr Gastroenterol Nutr 69, e39-e42.

Won, H., Lee, H.R., Gee, H.Y., Mah, W., Kim, J.I., Lee, J., Ha, S., Chung, C., Jung, E.S., Cho, Y.S., et al. (2012). Autistic-like social behaviour in Shank2-mutant mice improved by restoring NMDA receptor function. Nature 486, 261-265.

Yazejian, B., Sun, X.P., and Grinnell, A.D. (2000). Tracking presynaptic Ca2+ dynamics during neurotransmitter release with Ca2+-activated K+ channels. Nat Neurosci 3, 566571.

Yi, F., Danko, T., Botelho, S.C., Patzke, C., Pak, C., Wernig, M., and Sudhof, T.C. (2016). Autism-associated SHANK3 haploinsufficiency causes Ih channelopathy in human neurons. Science 352, aaf2669.

Yuan, A., Dourado, M., Butler, A., Walton, N., Wei, A., and Salkoff, L. (2000). SLO-2, a $\mathrm{K}+$ channel with an unusual Cl- dependence. Nat Neurosci 3, 771-779.

Zhang, H., Maximov, A., Fu, Y., Xu, F., Tang, T.S., Tkatch, T., Surmeier, D.J., and Bezprozvanny, I. (2005). Association of CaV1.3 L-type calcium channels with Shank. J Neurosci 25, 1037-1049.

Zhou, Y., Kaiser, T., Monteiro, P., Zhang, X., Van der Goes, M.S., Wang, D., Barak, B., Zeng, M., Li, C., Lu, C., et al. (2016). Mice with Shank3 Mutations Associated with ASD and Schizophrenia Display Both Shared and Distinct Defects. Neuron 89, 147-162.

Zhu, M., Idikuda, V.K., Wang, J., Wei, F., Kumar, V., Shah, N., Waite, C.B., Liu, Q., and Zhou, L. (2018). Shank3-deficient thalamocortical neurons show HCN channelopathy and alterations in intrinsic electrical properties. J Physiol 596, 1259-1276. 
Table 1. Comparison of shn-1 null alleles

\begin{tabular}{lllll}
\hline \hline Genotype: & PP rate $(\mathrm{Hz}):$ & AP width $(\mathrm{ms}):$ & AP amp. $(\mathrm{mV}):$ & RMP $(\mathrm{mV}):$ \\
\hline WT & $0.01 \pm 0.00$ & $26.73 \pm 1.98$ & $40.42 \pm 0.77$ & $-12.61 \pm 0.96$ \\
shn-1(nu712) & $0.04 \pm 0.01^{\star \star}$ & $42.28 \pm 4.17^{\star \star \star}$ & $37.63 \pm 0.83^{*}$ & $-8.33 \pm 0.72^{\star \star}$ \\
shn-1(nu652) & $0.05 \pm 0.02^{\star \star \star}$ & $58.06 \pm 5.27^{\star \star \star}$ & $34.78 \pm 0.92^{\star \star \star}$ & $-7.19 \pm 0.99^{\star \star *}$ \\
shn-1(tm488) & $0.05 \pm 0.01^{\star \star \star}$ & $49.06 \pm 7.07^{\star \star \star}$ & $41.36 \pm 1.64$ & $-12.06 \pm 1.54$ \\
\hline \hline
\end{tabular}

Table 2. Alleles used in this study

\begin{tabular}{|c|c|c|}
\hline allele: & Description: & Reference: \\
\hline shn-1(tm488) & $1537 \mathrm{nt}$ deletion, frameshift at codon 118 & (Oh et al., 2011) \\
\hline shn-1(nu697) & LoxP sites in intron 1 and 3 'UTR & this study \\
\hline shn-1(nu>12) & derived by germline CRE recombination of $n u 697$ & this study \\
\hline shn-1(nu652) & $\begin{array}{l}\text { stop cassette (flanked by FLEX sites) in intron } 2 \text { in "OFF" } \\
\text { orientation }\end{array}$ & this study \\
\hline shn-1(nu600 GFP 11$)$ & 7 copies $\mathrm{GFP}_{11}$ inserted at codon 945 of SHN-1A & this study \\
\hline shn-1(nu542 $\Delta \mathrm{PDZ})$ & deletes aa $446-532$ of SHN-1A & this study \\
\hline egl-19(nu722 Cherry $\left.{ }_{11}\right)$ & 6 copies sfCherry ${ }_{11}$ inserted at codon 2 & this study \\
\hline egl-19(nu496 $\Delta \mathrm{VTTL})$ & $\begin{array}{l}\text { WT C-term PAENSSRQHDSRGGSQEDLLLVTTL replaced } \\
\text { with PMIHAEDHKKSYF }\end{array}$ & (Pym et al., 2017) \\
\hline slo-2(nu725 GFP $\left.{ }_{11}\right)$ & 7 copies GFP $_{11}$ inserted at codon 1092 of SLO-2A & this study \\
\hline slo-1 (nu678 GFP 11$)$ & 7 copies GFP $_{11}$ inserted at codon 1130 of SLO-1A & this study \\
\hline slo-1(js379) & Q251stop & (Wang et al., 2001) \\
\hline slo-2(nf100) & in frame deletion of aa $450-569$ & (Santi et al., 2003) \\
\hline shk-1(ok1581) & P253stop & (Liu et al., 2011) \\
\hline
\end{tabular}


bioRxiv preprint doi: https://doi.org/10.1101/2021.11.05.467415; this version posted November 5, 2021. The copyright holder has placed this preprint (which was not certified by peer review) in the Public Domain. It is no longer restricted by copyright. Anyone can legally share, reuse, remix, or adapt this material for any purpose without crediting the original authors.

A
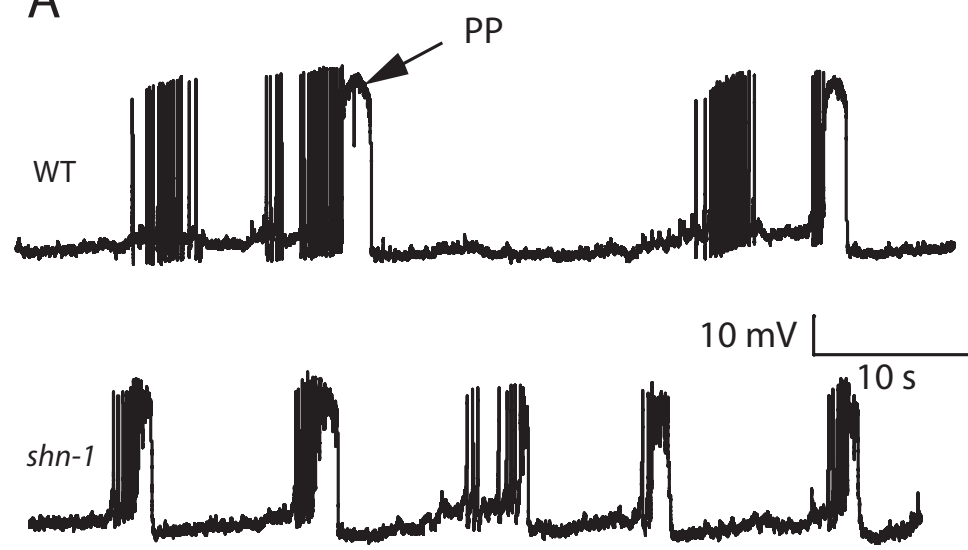

B

C

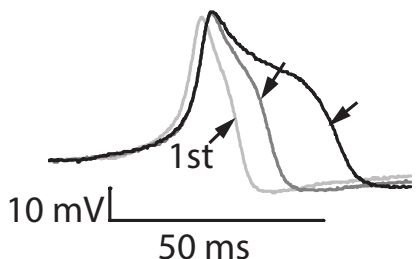

D

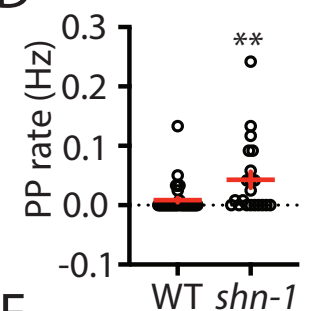

$\mathrm{F}$
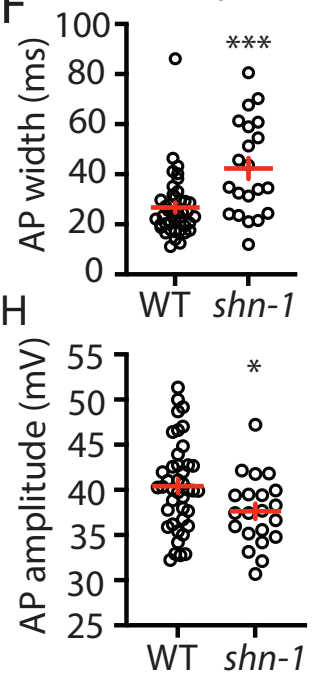

E

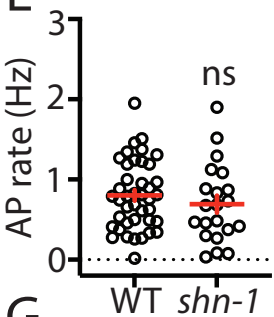

G

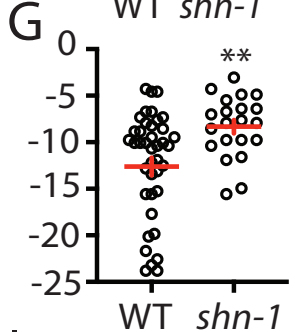

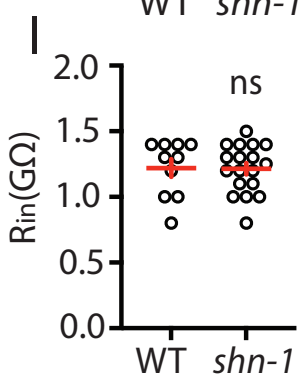

Figure 1. Gao et al. 
bioRxiv preprint doi: https://doi.org/10.1101/2021.11.05.467415; this version posted November 5, 2021. The copyright holder has placed this preprint (which was not certified by peer review) in the Public Domain. It is no longer restricted by copyright. Anyone can legally share, reuse,
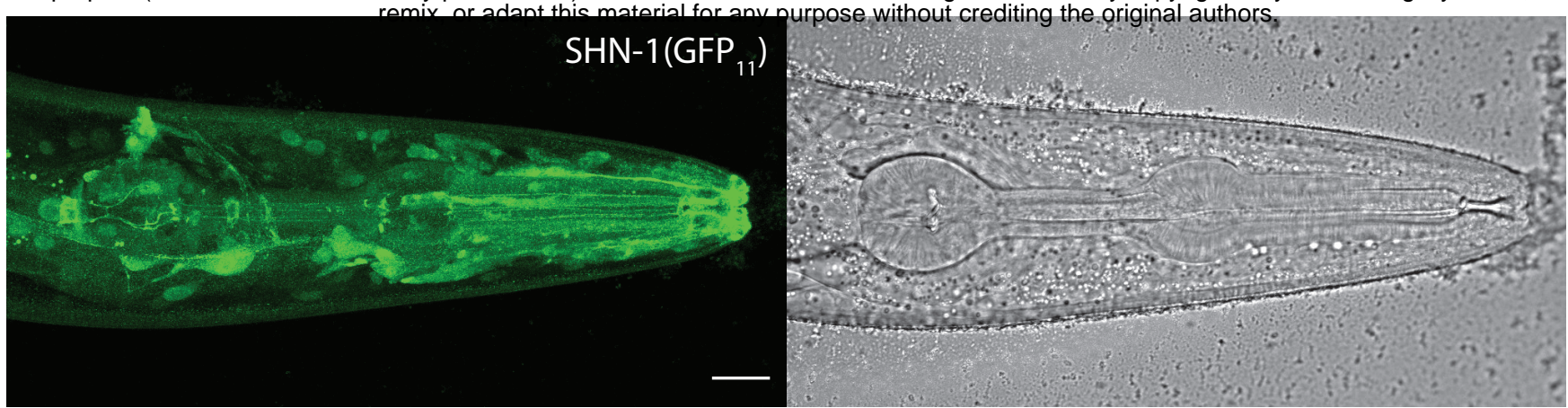

Gao et al, Figure 1, Supplement 1 
bioRxiv preprint doi: https://doi.org/10.1101/2021.11.05.467415; this version posted November 5, 2021. The copyright holder has placed this $A$ preprint (which was not certified by peer review) in the Public Domain. It is no longer restricted by copyright. Anyone can legally share, reuse A nu697 remix, or adapt this material for any purpose without crediting the original authors.

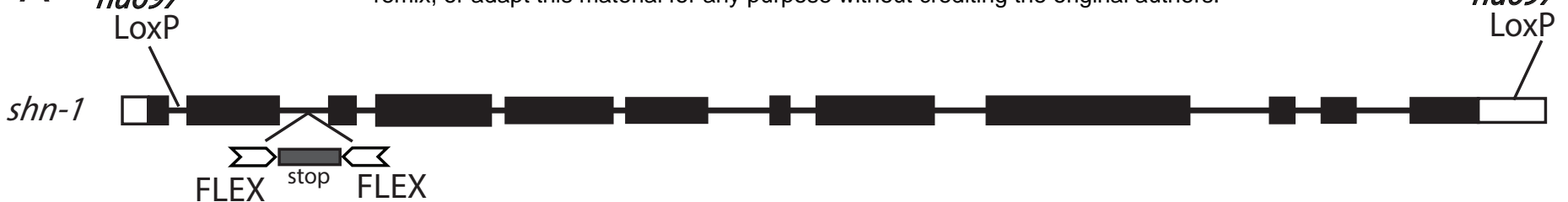
nu652

B
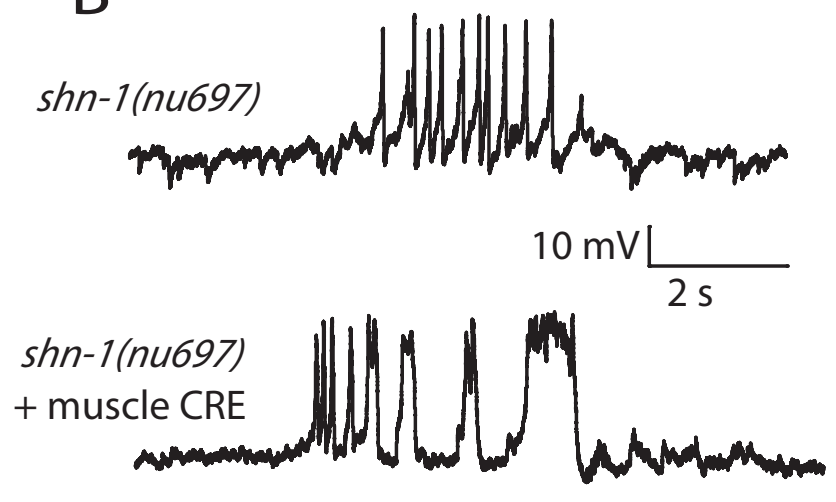

C

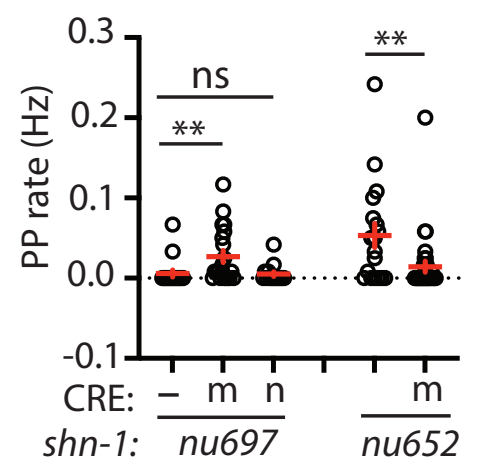

D

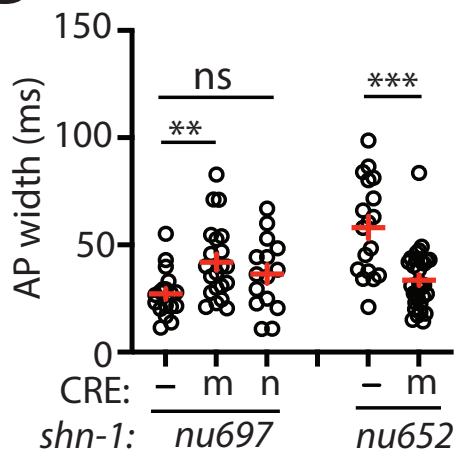

Figure 2. Gao et al. 
A

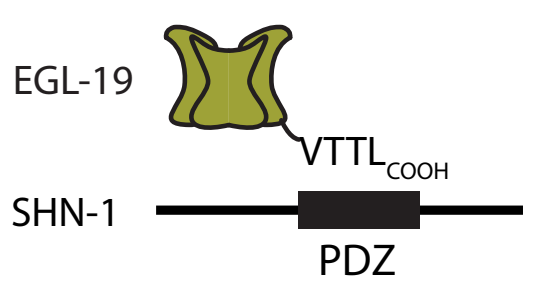

B

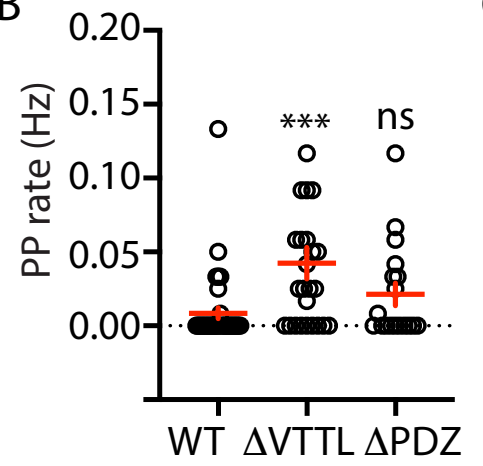

C

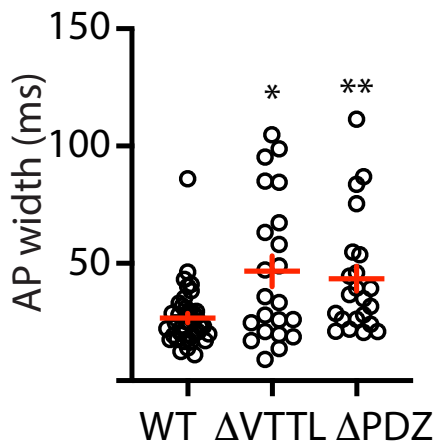

Figure 3. Gao et al. 
bioRxiv preprint doi: https://doi.org/10.1101/2021.11.05.467415; this version posted November 5, 2021. The copyright holder has placed this preprint (which was not certified by peer review) in the Public Domain. It is no longer restricted by copyright. Anyone can legally share, reuse, remix, or adapt this material for any purpose without crediting the original authors.

A

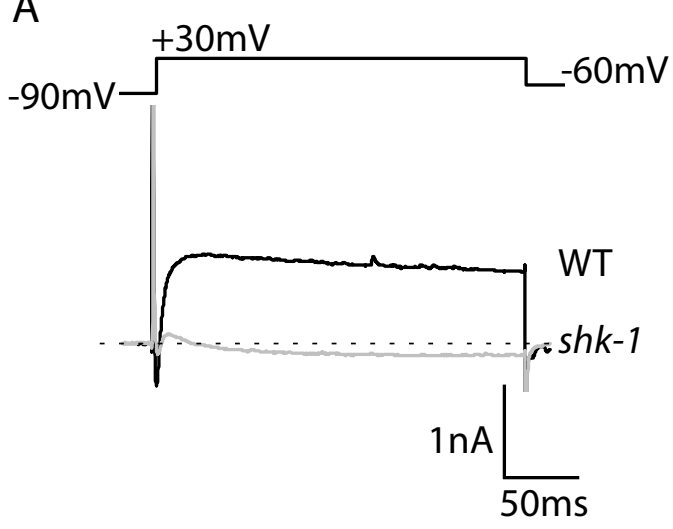

C

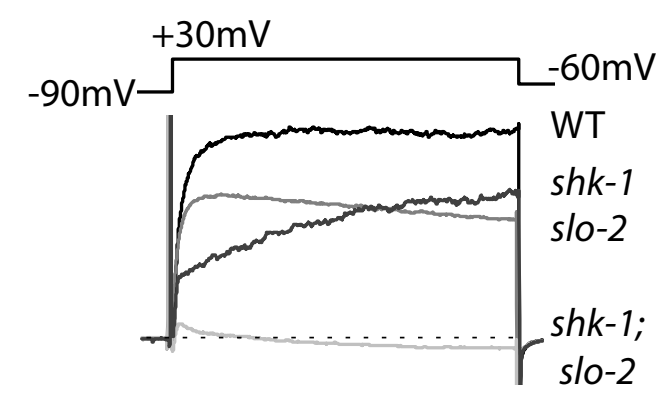

B

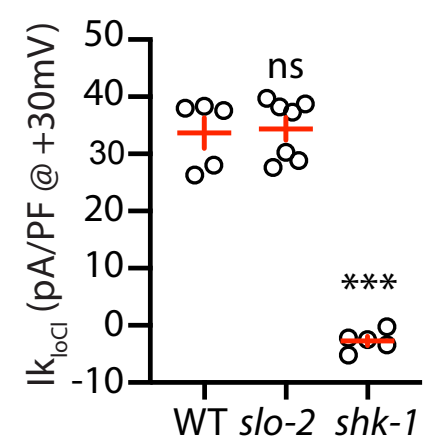

D

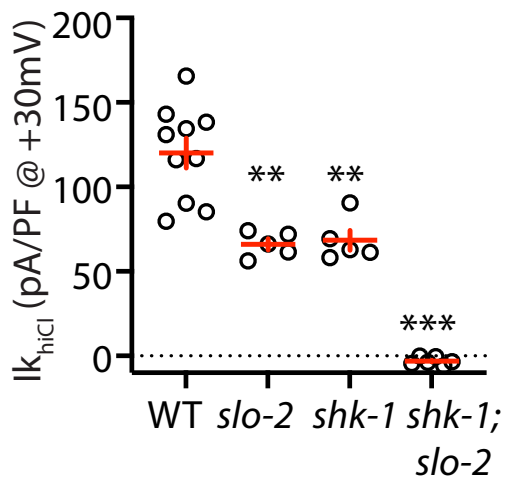

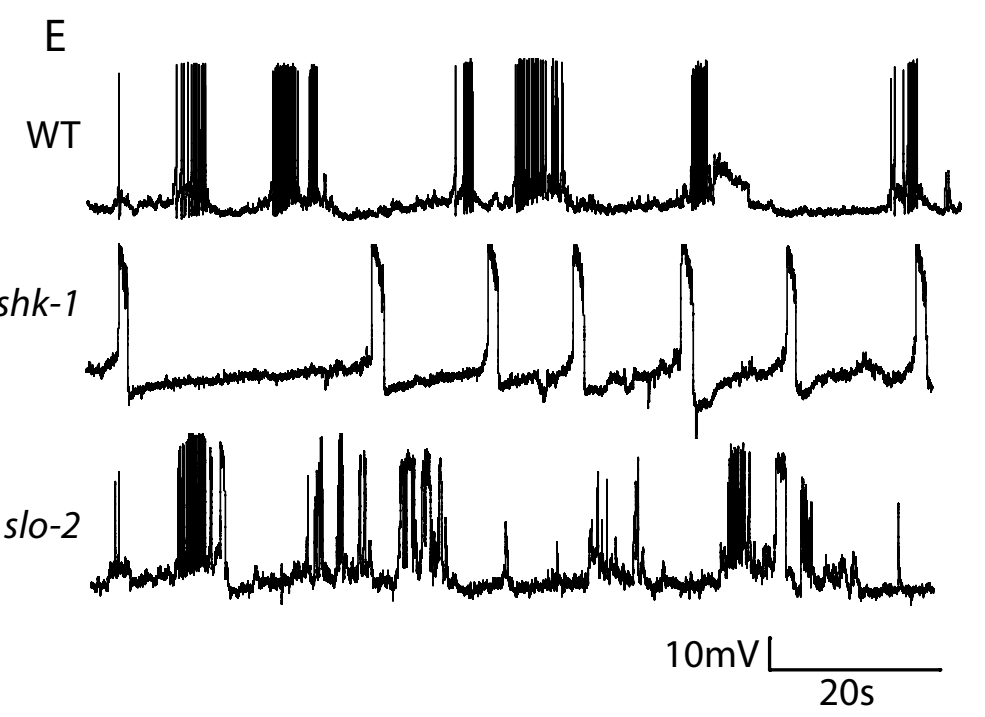

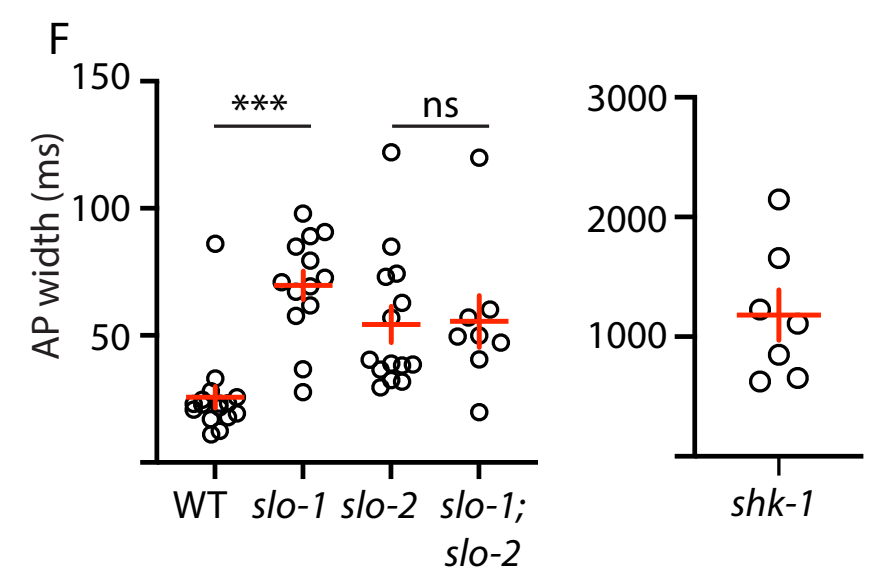

Figure 4. Gao et al. 


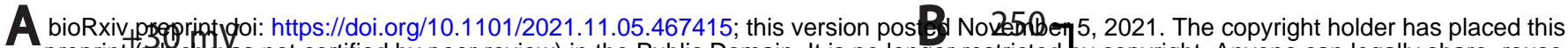
preprint (which was not certified by peer review) in the Public Domain. It is no longer restricted by copyright. Anyone can legally share, reuse, $-90 \mathrm{mV}$
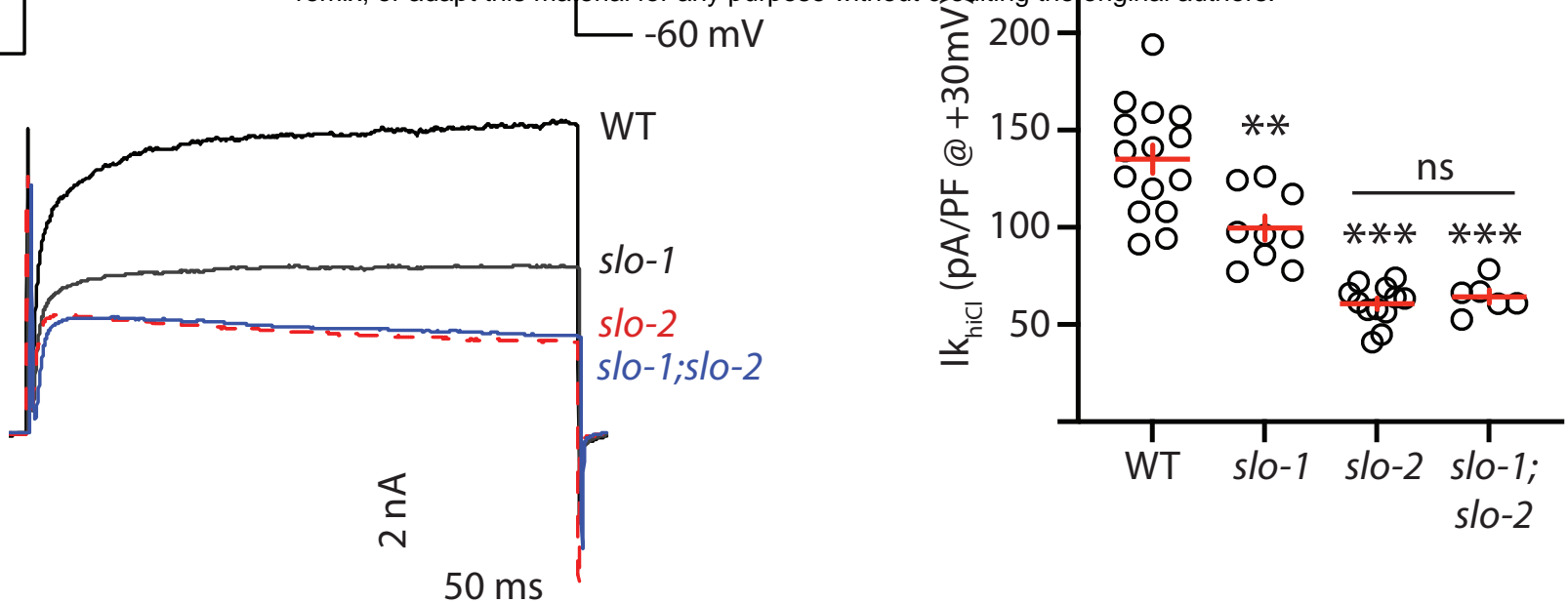

C
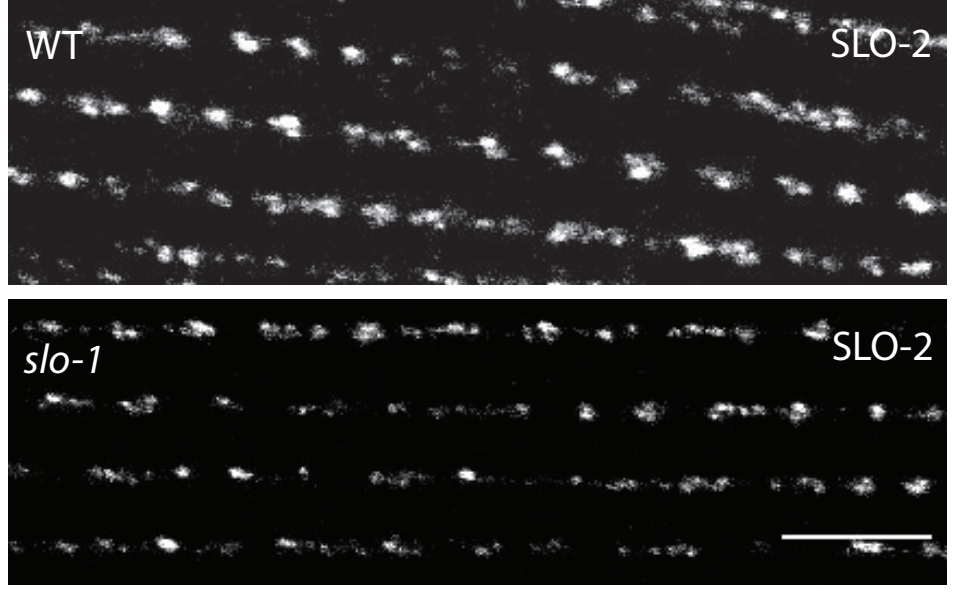

E
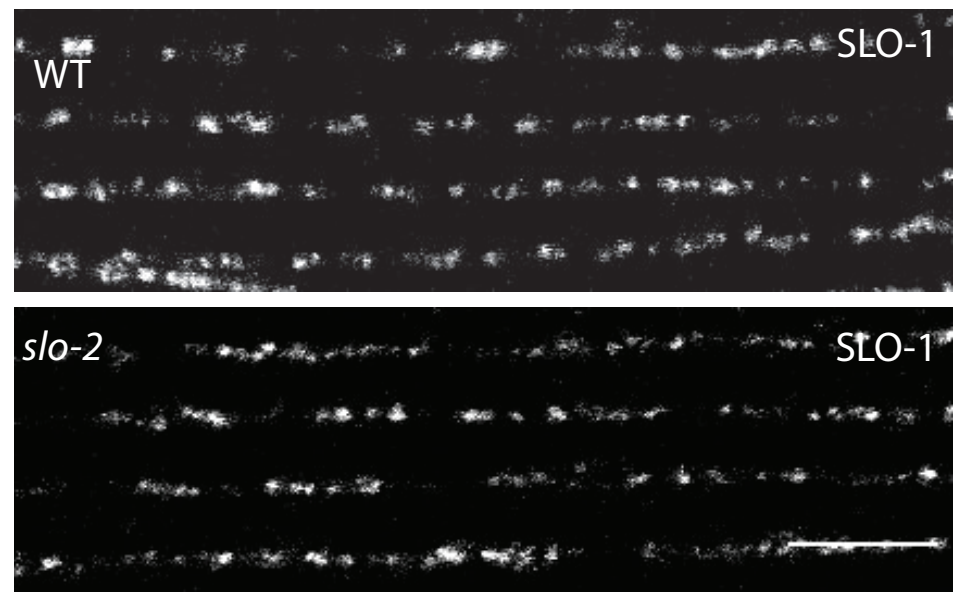

D
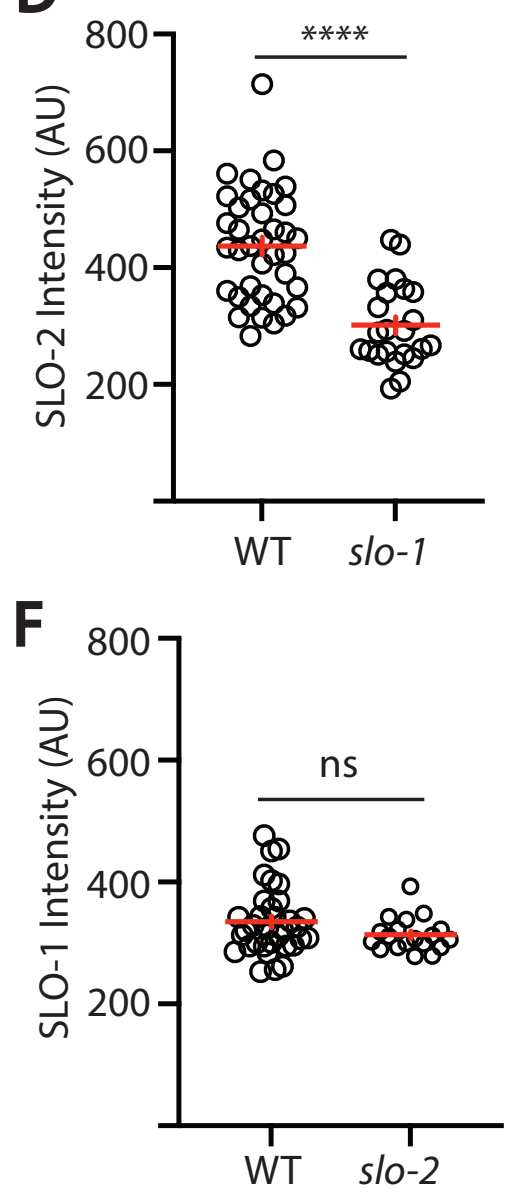

Figure 5. Gao et al. 

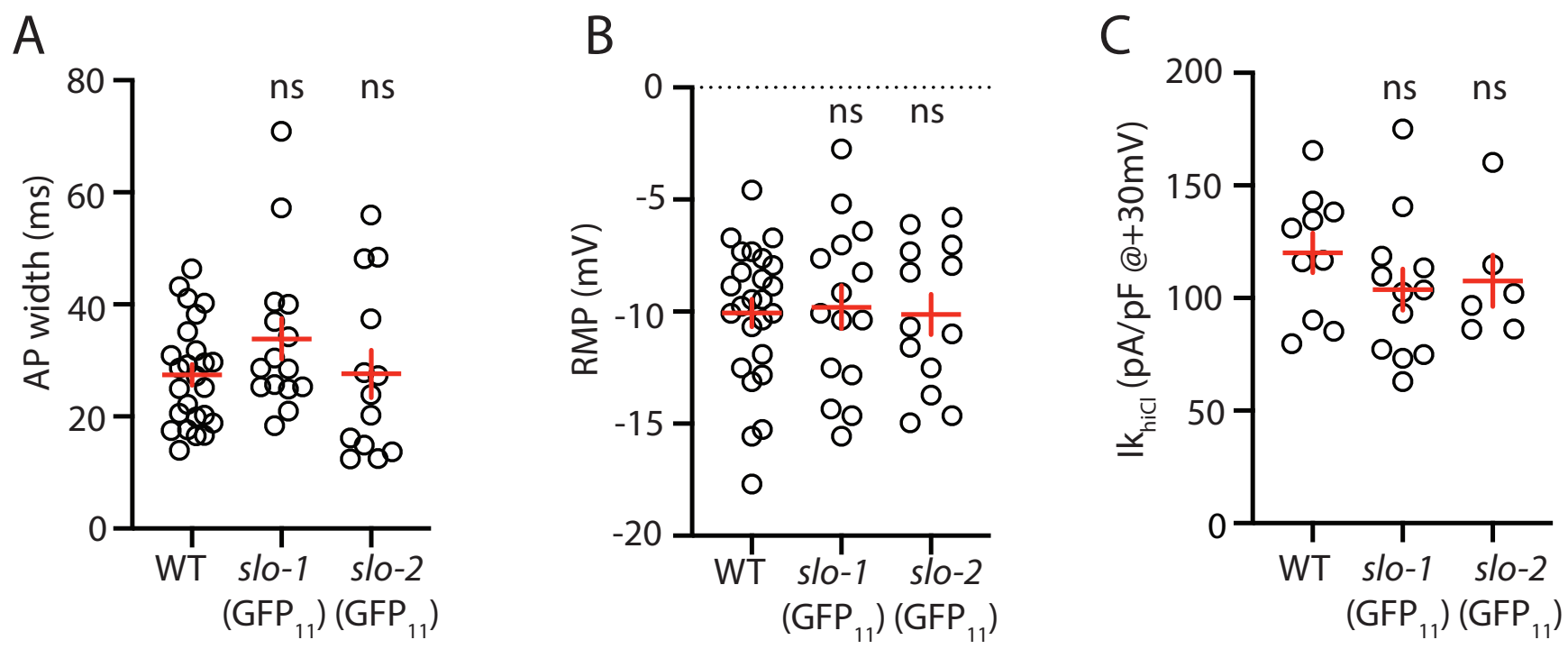

Figure 5 Supplement 1. Gao et al. 
bioRxiv preprint doi: https://doi.org/10.1101/2021.11.05.467415; this version posted November 5, 2021. The copyright holder has placed this preprint (which was not certified by peer review) in the Public Domain. It is no longer restricted by copyright. Anyone can legally share, reuse,

A

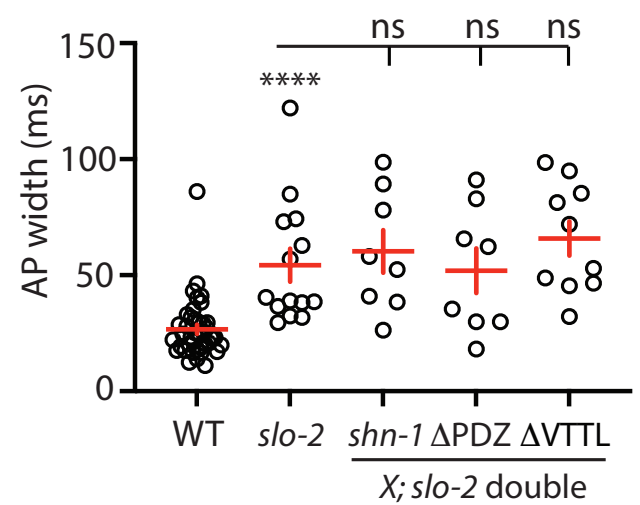

D
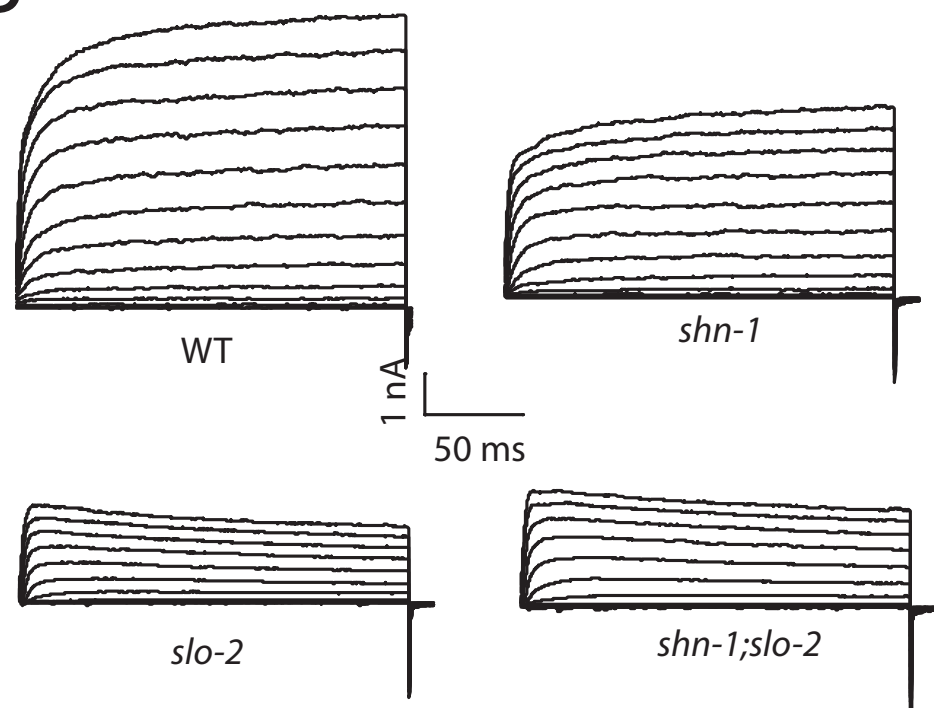

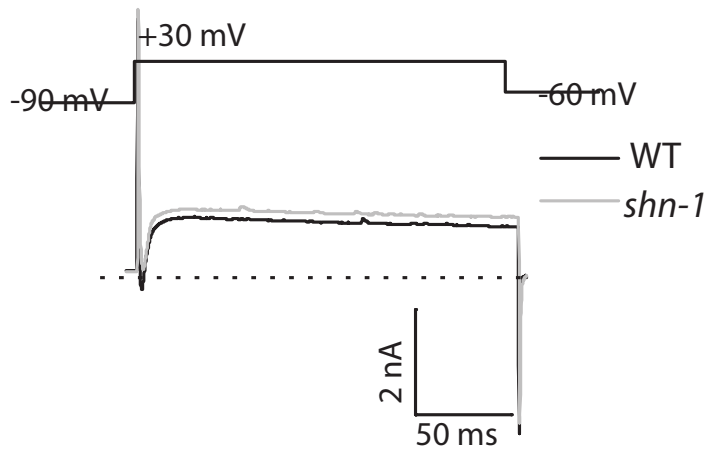

E

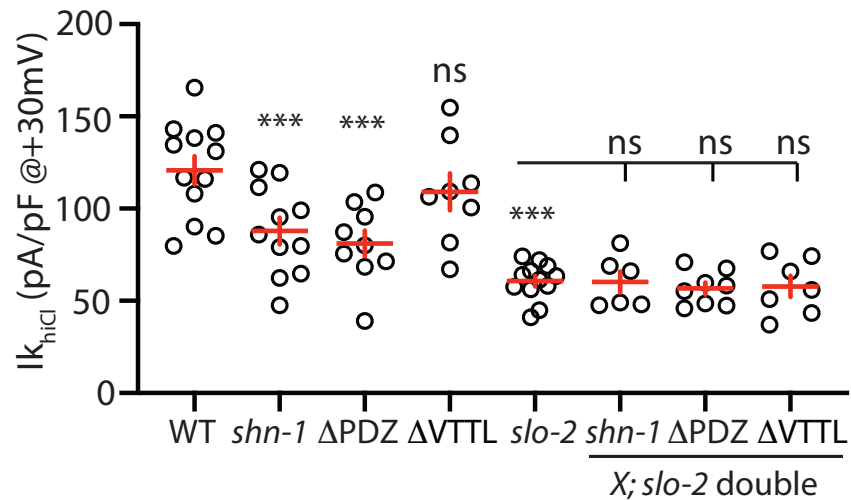

Figure 6. Gao et al. 
bioRxiv preprint doi: https://doi.org/10.1101/2021.11.05.467415; this version posted November 5, 2021. The copyright holder has placed this A preprint (which was not certified by peer review) in the Public Domain. It $\mathbf{B}$ no longer restricted by copyright. Anyone can legally share, reuse,

WT

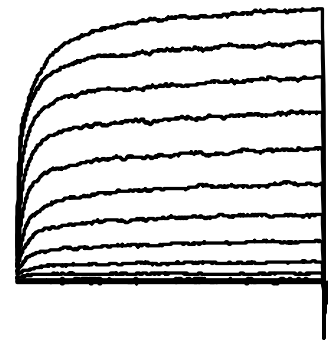
remix, of adzpt this material for any purpose without crediting the original authors.

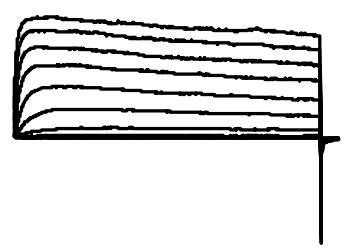

C

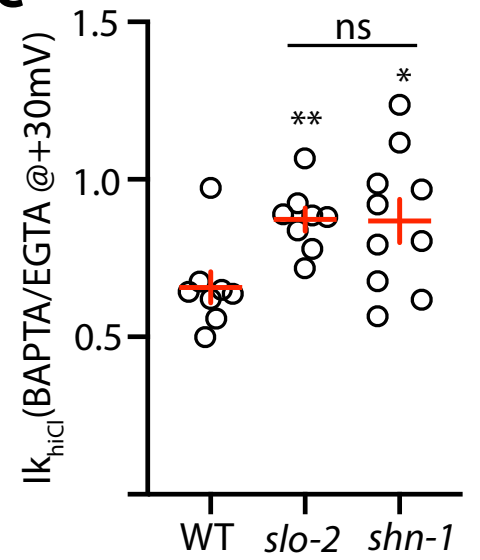

F

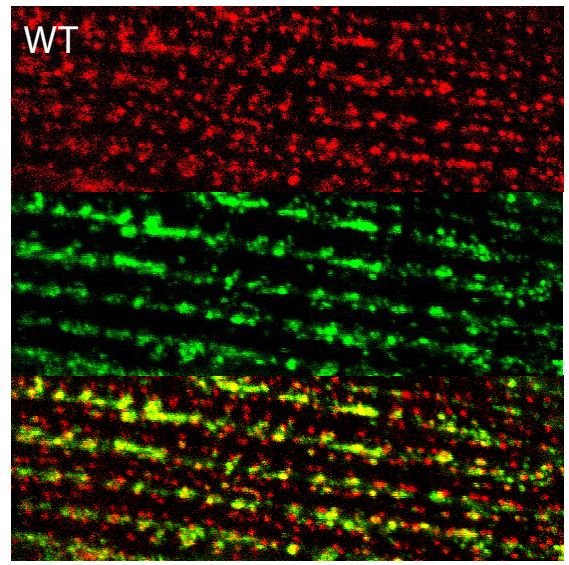

D

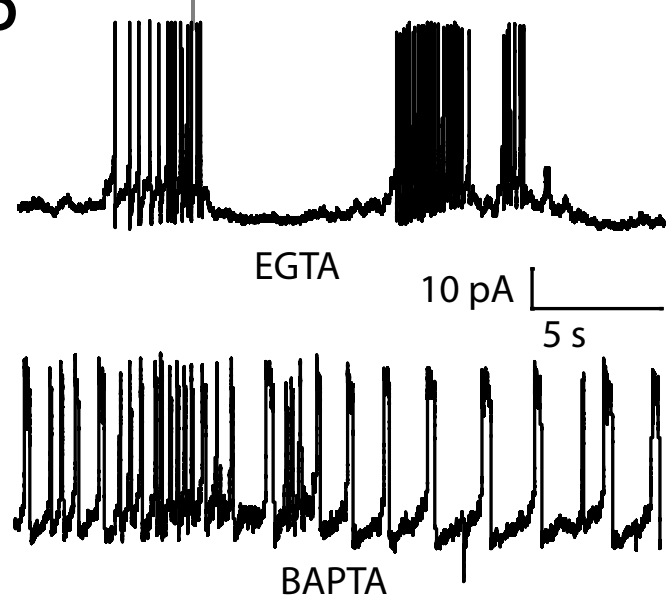

G

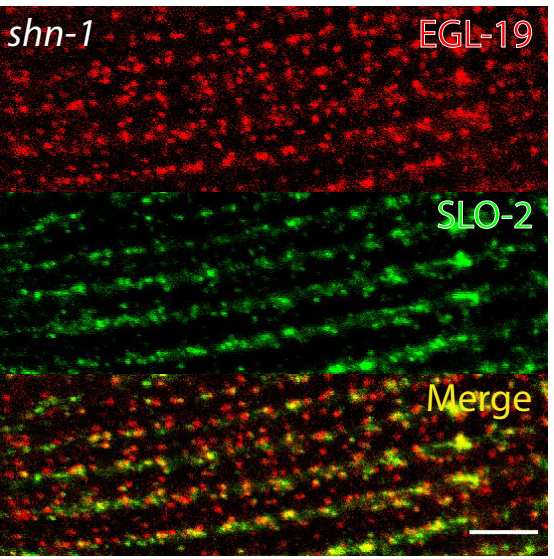

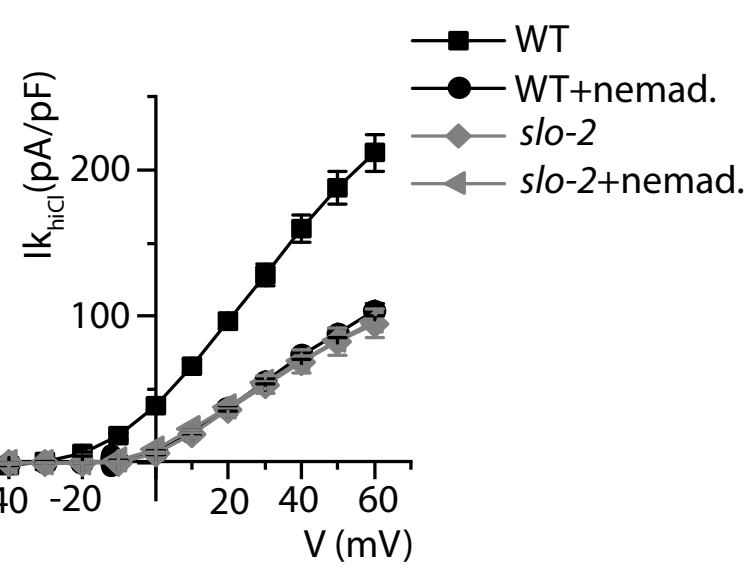

E

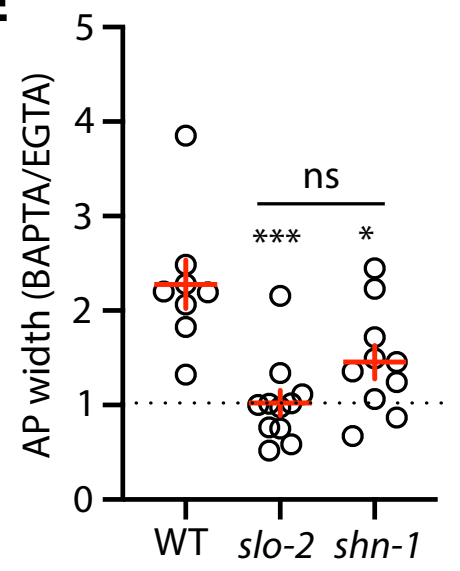

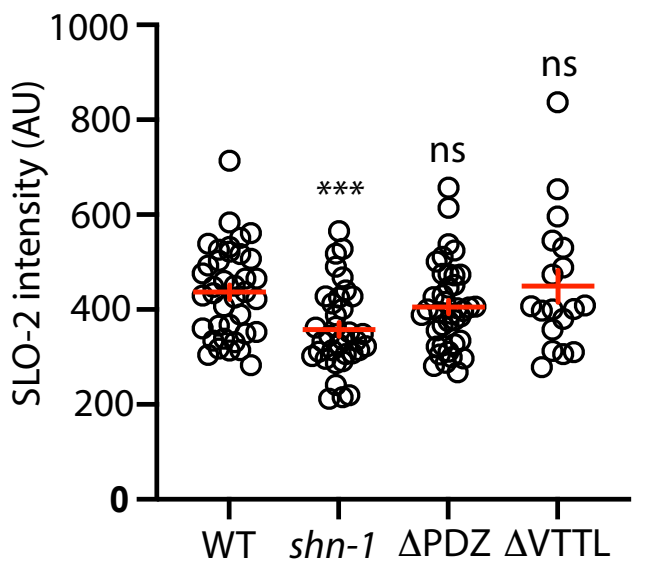

Figure 7. Gao et al. 
bioRxiv preprint doi: https://doi.org/10.1101/2021.11.05.467415; this version posted November 5, 2021. The copyright holder has placed this preprint (which was not certified by peer review) in the Public Domain. It is no longer restricted by copyright. Anyone can legally share, reuse, remix, or adapt this material for any purpose without crediting the original authors.

A
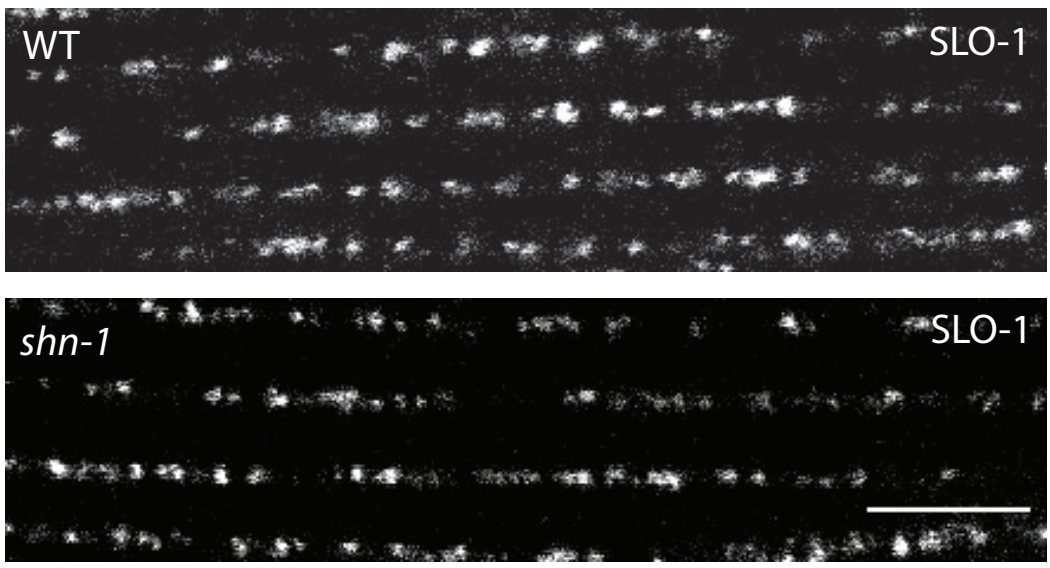

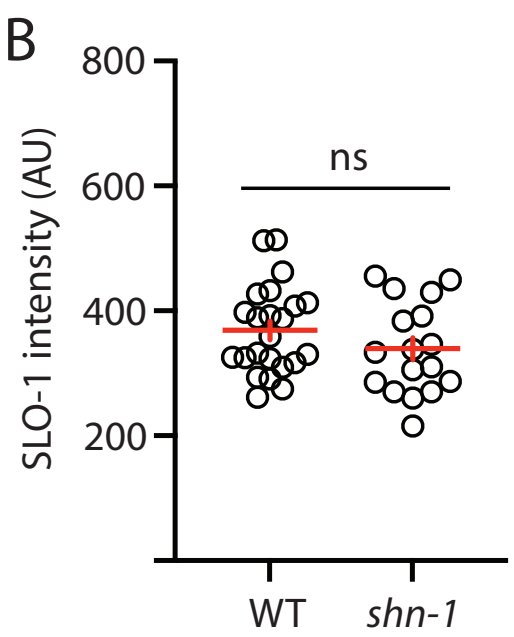

Figure 7 Supplement 1. Gao et al. 
bioRxiv preprint doi: https://doi.org/10.1101/2021.11.05.467415; this version posted November 5, 2021. The copyright holder has placed this preprint (which was not certified by peer review) in the Public Domain. It is no longer restricted by copyright. Anyone can legally share, reuse, remix, or adapt this material for any purpose without crediting the original authors.
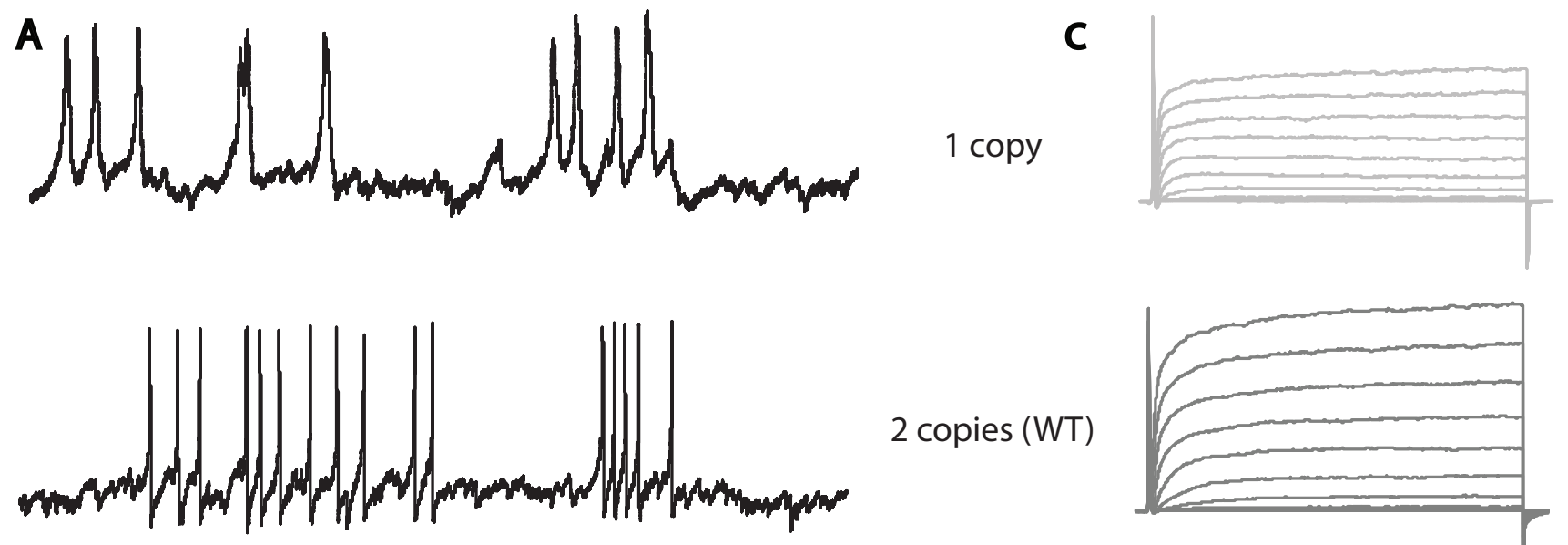

2 copies (WT)
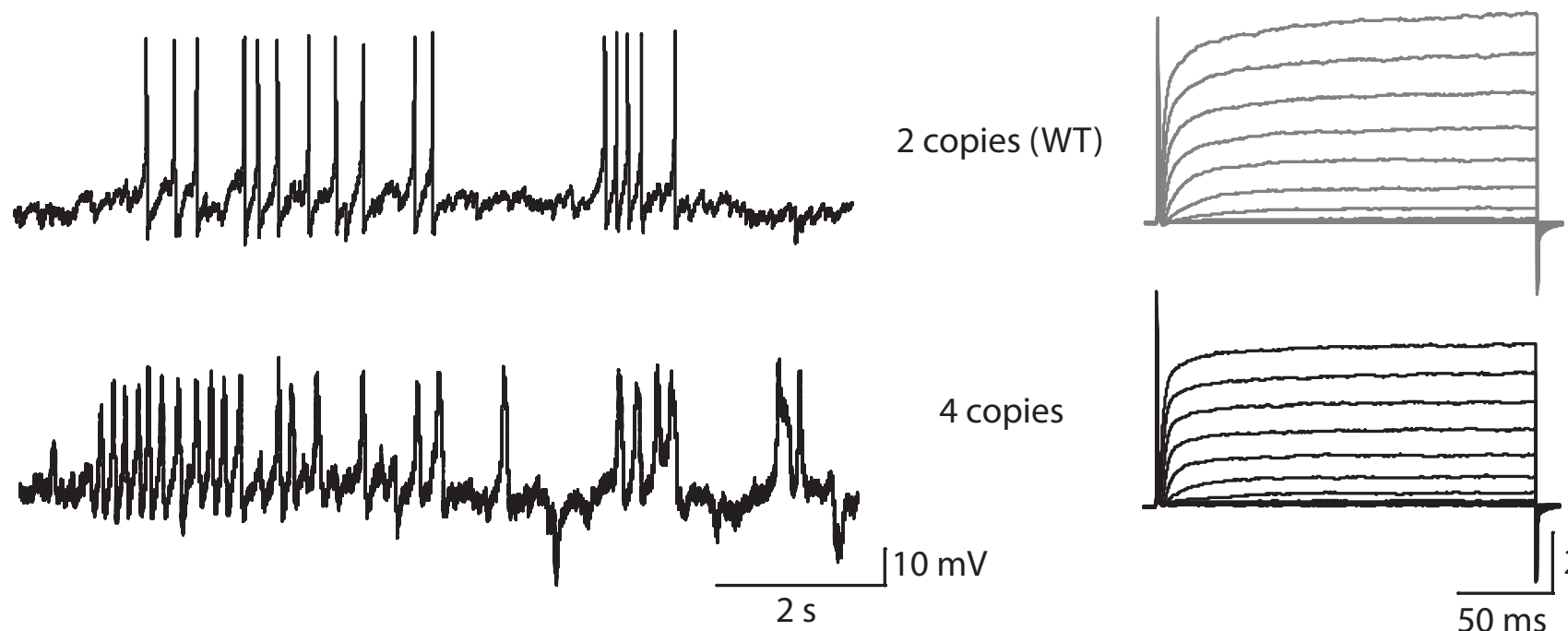

B

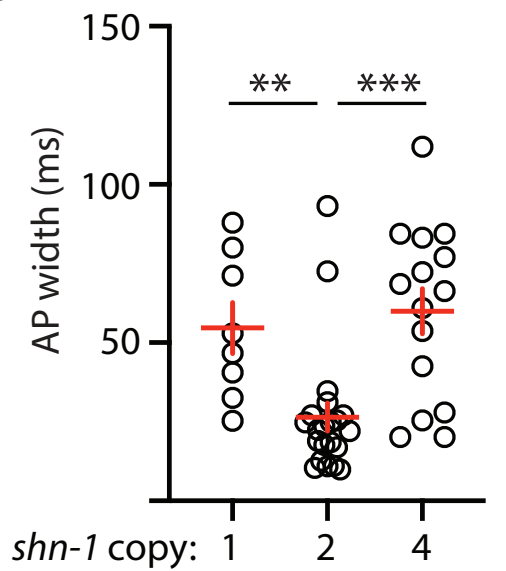

D

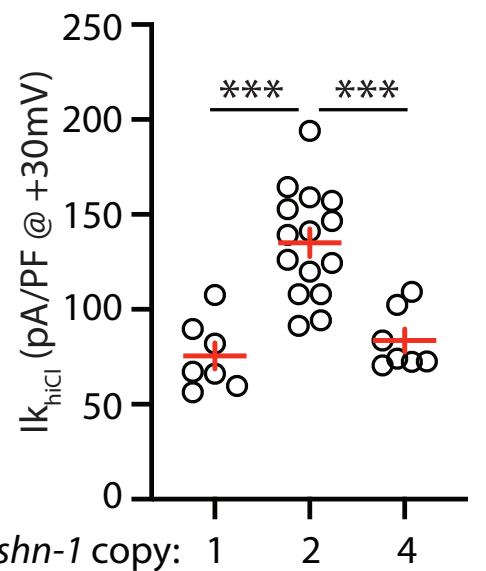

Figure 8. Gao et al. 
bioRxiv preprint doi: https://doi.org/10.1101/2021.11.05.467415; this version posted November 5, 2021. The copyright holder has placed this prepint (which was not certified by peer review) in the Public Domain. It is no longer restricted by copyright. Anyone can legally share, reuse, remit, or adapt this material for any purpose without crediting the/griginal authors.
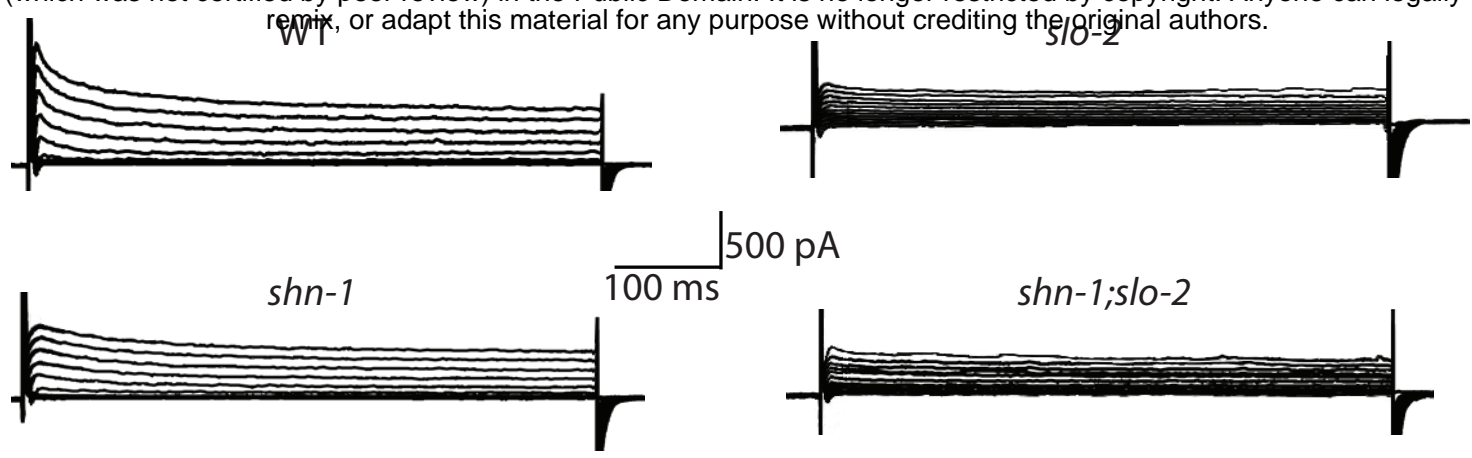

$500 \mathrm{pA}$

B
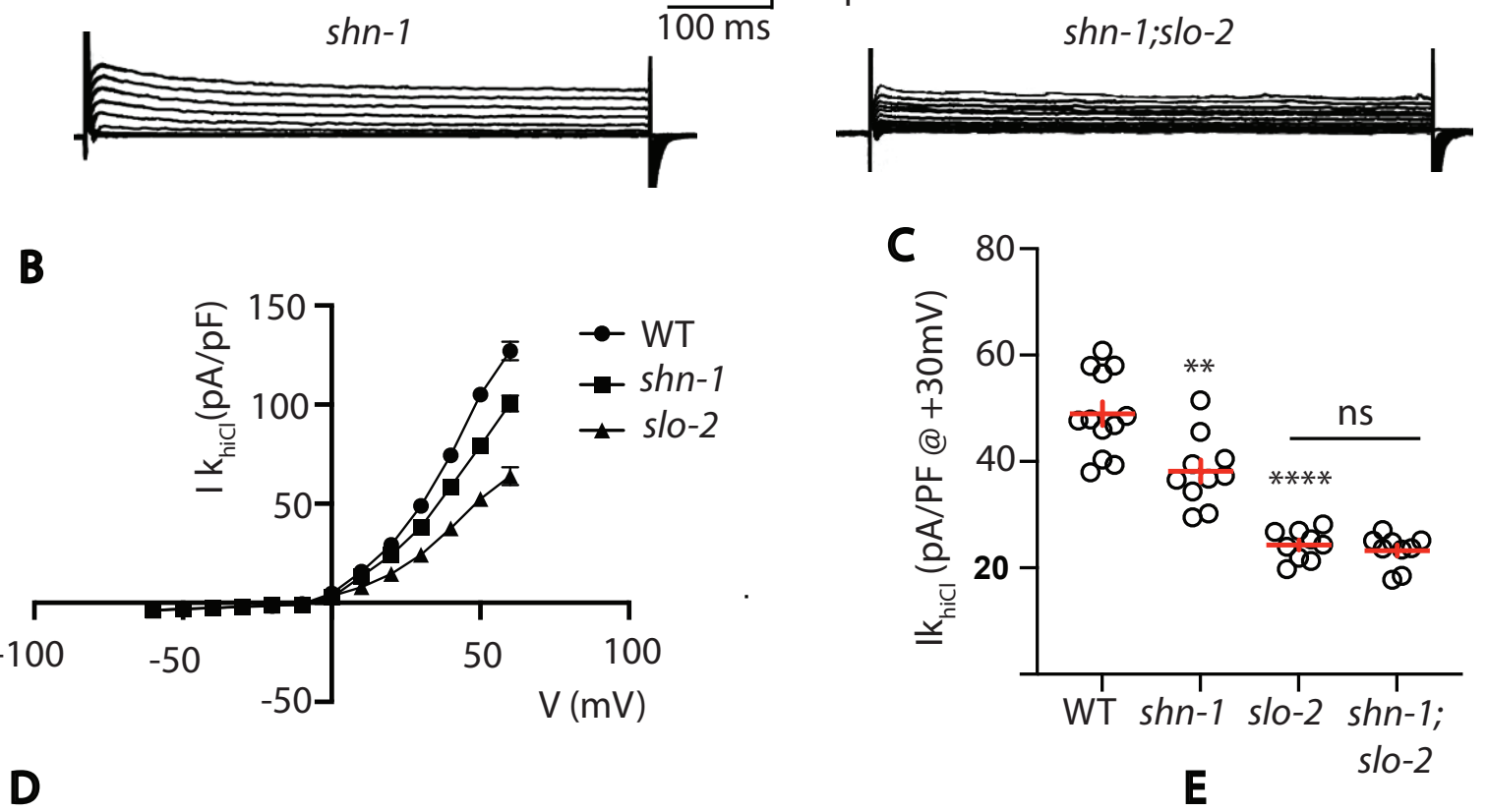

D
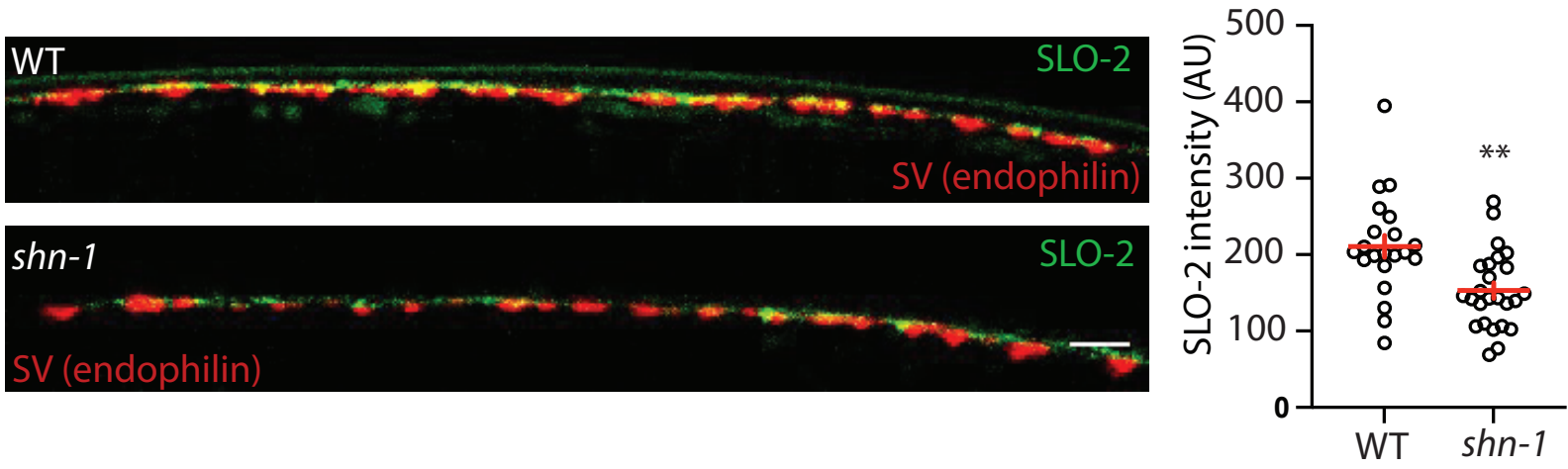

Figure 9. Gao et al. 